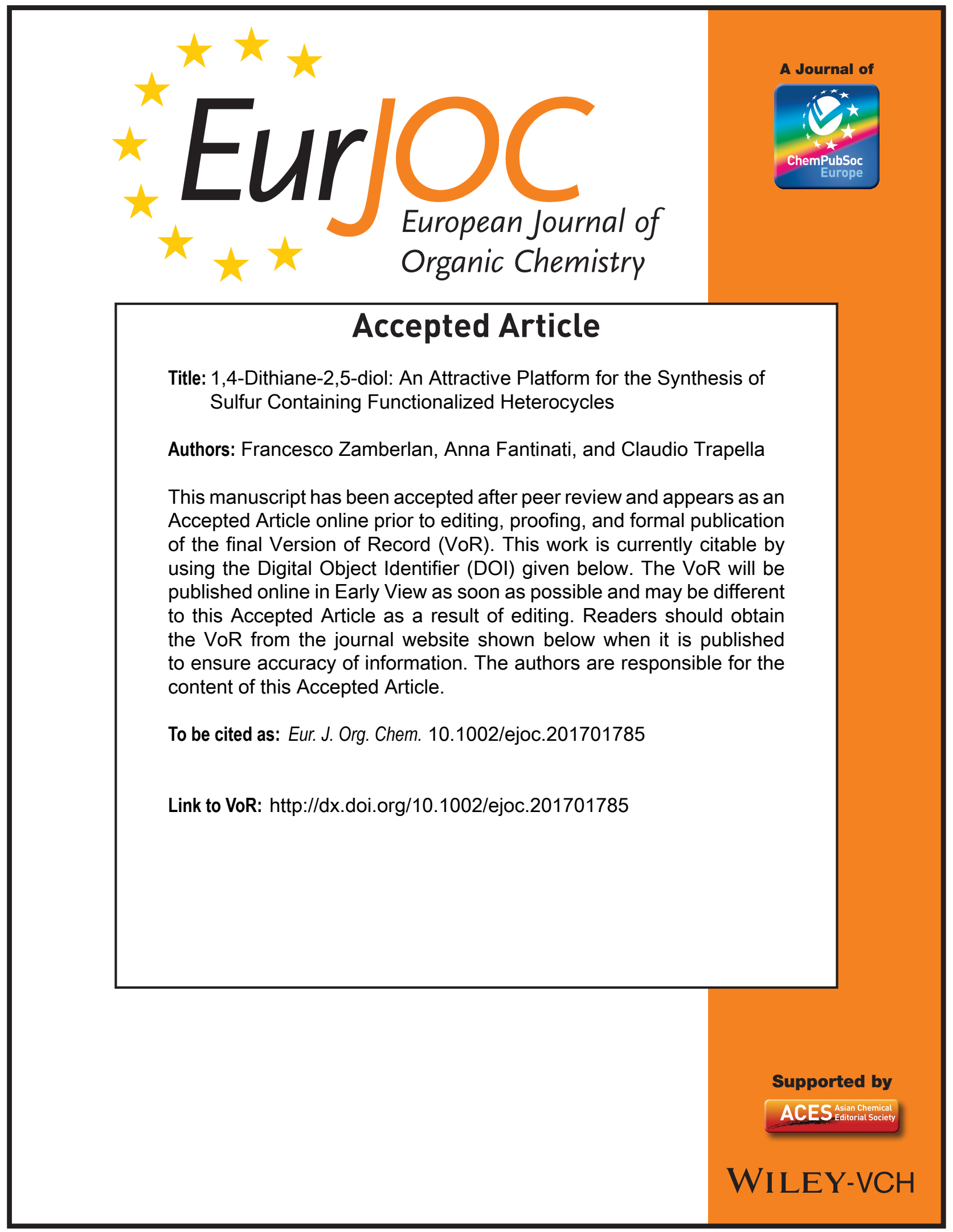




\title{
1,4-Dithiane-2,5-diol: An Attractive Platform for the Synthesis of Sulfur Containing Functionalized Heterocycles
}

\author{
Francesco Zamberlan, ${ }^{[\mathrm{a}]}$ Anna Fantinati, ${ }^{[\mathrm{b}]}$ Claudio Trapella ${ }^{*[\mathrm{~b}]}$ \\ Dedicated to Professor Simonetta Benetti on the occasion of her retirement
}

\begin{abstract}
This microreview highlights the utility of 1,4- dithiane-2,5diol 1 as a source for the in situ generation of 2mercaptoacetaldehyde 2, a versatile two-carbon synthon featuring both electrophilic and nucleophilic reaction centers widely utilized as an attractive platform for the preparation of sulfur-containing molecules. We discussed the involved chemistry, mainly focusing on its applications to the construction of sulfur-containing heterocyclic compounds including the thiophene and 1,3-thiazole families and other different sulfur-nitrogen and sulfur-oxygen heterocycles which continue to be a pillar of organic synthesis as a result of their broad application in organic and medicinal chemistry.
\end{abstract}

\section{Introduction}

The development of highly efficient synthetic methods to access sulfur-containing heterocycles, privileged structural units featuring many biologically active natural and synthetic compounds, is particularly appealing. ${ }^{[1,2]}$ Compared with other starting materials, 1,4-dithiane-2,5-diol, 1, the dimer of mercaptoacetaldehyde 2 , has emerged as an attractive platform for the preparation of these frameworks (Scheme 1).<smiles>OC1CSC(O)CS1</smiles>

1
2

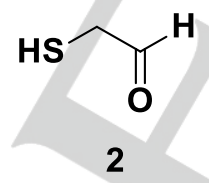

Scheme 1 Formation of 2-mercaptoacetaldehyde from 1,4-dithiane-2,5-diol.

Indeed, the bifunctional nature of mercaptoacetaldehyde $\mathbf{2}$ easily released in situ by treatment with tertiary amines or certain organocatalysts from the dimeric hemithioacetal 1 , could take part as a versatile two-carbon synthon in a variety of domino thia-Michael/aldol reactions. This microreview describes the chemistry of 1,4-dithiane-2,5-diol, mainly focusing on its applications to the construction of different sulfur-containing heterocycles, including tetrahydrothiophene, dihydrothiophene and thiophene derivatives as well as 1,3-thiazole and

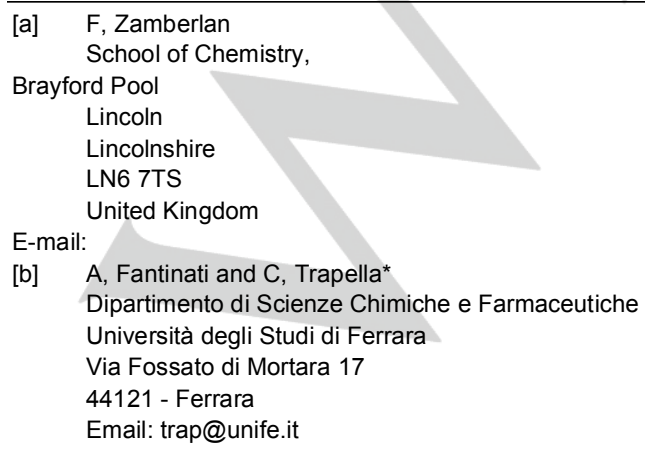

[b] A, Fantinati and C, Trapella*

Dipartimento di Scienze Chimiche e Farmaceutiche

Università degli Studi di Ferrara

Via Fossato di Mortara 17

44121 - Ferrara

Email: trap@unife.it

thiazolidine derivatives, 1,3-oxathiolanes, tetrahydropyranols and other sulfur-nitrogen and sulfur-oxygen heterocyclic compounds. Indeed, 1,4-dithiane-2,5-diol $\mathbf{1}$ has been and continues to be widely used in organic synthesis, its utilization being greatly facilitated by the commercial availability.

Claudio Trapella was born in Ferrara in 1972 , completed his $\mathrm{PhD}$ in pharmaceutical sciences in 2002 and is now assistant professor of organic chemistry. The main research interests are focused in the organotransition metal chemistry for the synthesis of biological active compounds especially in the pain field.

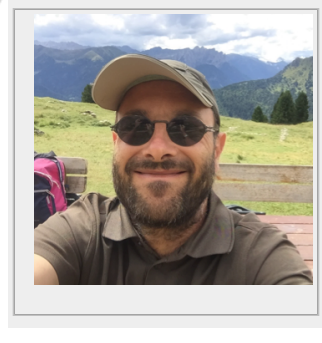

Anna Fantinati was born in Rovigo in 1990. She is a PhD student in organic chemistry and her main research interests are focused in the synthesis of bio-active spirocompounds mitochondria target.

Francesco Zamberlan was born in Ferrara in 1984, and obtained his $\mathrm{PhD}$ in chemical sciences in 2013 from the University of Ferrara. After a few years of postdoctoral work at the University of Nottingham, he is now a lecturer in Organic Chemistry at the University of Lincoln. His research interests are in the field of chemical biology and bioimaging.

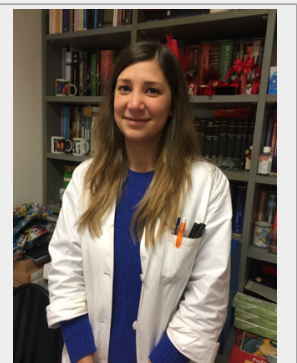

\section{The Thiophene family}

Thiophene derivatives, as well as the partially reduced 2,3- or 2,5-dihydrothiophene, or the totally reduced tetrahydrothiophene ring systems, are unique sulfur-containing heterocycles that have attracted a lot of attention, particularly because of their special place as natural products' building blocks. ${ }^{[1,2]}$

\subsection{Tetrahydrothiophene synthesis}

Tetrahydrothiophenes are important motifs in the context of natural as well as non-natural, biologically active compounds, 
and materials chemistry. ${ }^{[1,2]}$ In 1992, Effenberger and co-workers described an approach to 5-thio- $D$-xylulofuranoses 5 and 6 using rabbit muscle aldolase- (RAMA)-catalyzed reaction of mercaptoacetaldehyde with dihydroxyacetonephosphate $\mathbf{3}$, which is likely the first utilization of 1,4-dithiane-2,5-diol $\mathbf{1}$ for the synthesis of the tetrahydrothiophene moiety. ${ }^{[3]}$ After the initial aldol reaction, the product $\mathbf{4}$ was dephosphorylated by means of an acid phosphatase (Scheme 2).

$$
1+{ }_{\mathrm{H}_{2} \mathrm{O}, \mathrm{pH} 4.5}
$$

Scheme 2: First utilisation of 1 in the synthesis of tetrahydrothiophenes.

Later, the construction of tetrahydrothiophen-3-ol derivatives focused on the use of $\mathbf{1}$ as a versatile two-carbon synthon able to readily take part in [3+2] annulation reactions with activated carbon-carbon double bonds, providing rapid access to tetrahydrothiophenes.

In 2006, Pollini and co-workers exploited the reactivity of mercaptoacetaldehyde for tandem Michael-Henry or MichaelMichael reactions with electrophilic alkenes, resulting in the facile formation of 3,4-disubstituted tetrahydrothiophenes 8 using in situ generated nitroalkenes from the stable precursors $\beta$-nitroacetates $\mathbf{7}$ as the electrophilic partner of mercaptoacetaldehyde (Scheme 3). ${ }^{[4]}$

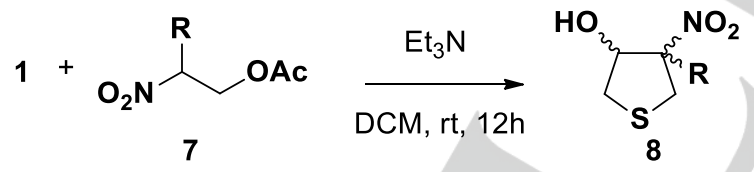

$$
\begin{aligned}
& 65 / 80 \% \text { yield } \\
& \mathrm{R}=\mathrm{H}, \mathrm{CH}_{2} \mathrm{OH},\left(\mathrm{CH}_{2}\right)_{2} \mathrm{OCH}_{2} \mathrm{OMe}
\end{aligned}
$$

Scheme 3: Mercaptoacetaldehyde use in tandem Michael-Henry for the formation of 3,4-disubstituted tetrahydrothiophnes.

Moreover, the mild protocol developed by Bunce and Pierce for the reaction of 1 with the stabilized triphenylphosphorane 9a-c or phosphonate 10 allowed to obtain 4-mercapto-2-butenoates 11a-d, valuable four-carbon units suitable for sulfaMichael/aldol(Henry) type cascade reactions to produce differently substituted tetrahydrothiophenes 12 (Scheme 4). ${ }^{[5]}$

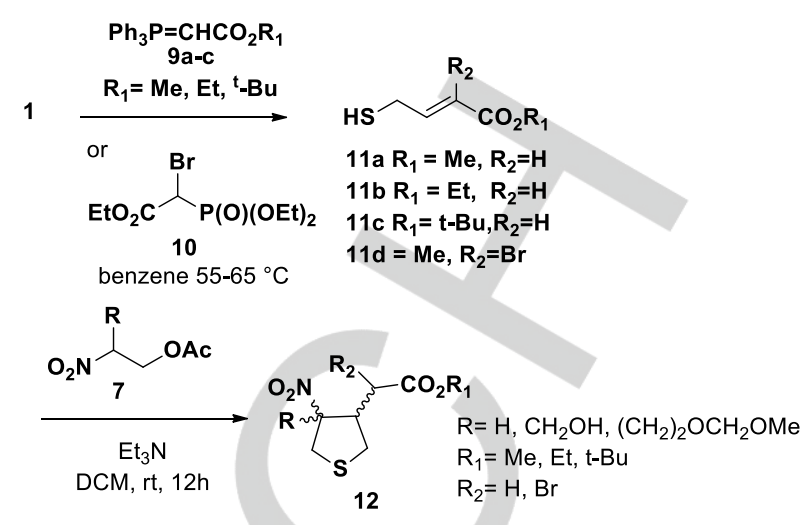

Scheme 4: Use of 1 to obtain obtain 4-mercapto-2-butenoates and subsequent use in sulfa-Michael/aldol(Henry) cascade reactions.

Since these seminal publications, the stereoselective synthesis of chiral tetrahydrothiophenes with high atom efficiency and, more importantly, good feasibility, has become a very hot topic in current research efforts.

In 2007, Wang and co-workers ${ }^{[6]}$ introduced the enantioselective domino thio-Michael-Michael process to furnish chiral tetrahydrothiophenes. Thus, trans-ethyl 4-mercapto-2-butenoate 11b has been used as reaction partner of $\alpha, \beta$-unsaturated aldehydes in an asymmetric organocatalytic domino MichaelMichael addition reaction in the presence of (S)-diphenylprolinol TMS ether. Aromatic aldehydes bearing neutral, electrondonating or electron-withdrawing groups, as well as heteroaromatic and aliphatic $\alpha, \beta$-unsaturated aldehydes 13 took easily part to the reaction affording chiral tetrahydrothiophenes 14 containing three stereogenic centers in good to excellent enantio- $(94-99 \%)$ and diastereoselectivities $(6: 1$ to $18: 1)$ (Scheme 5).
$11 b$

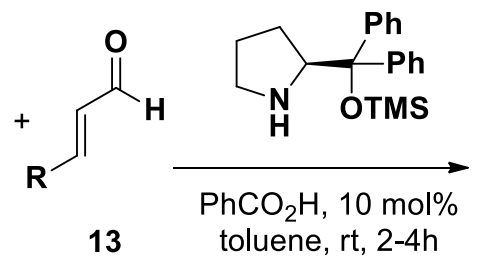<smiles>[R]C1SC[C@@H](CC(=O)OCC)[C@@H]1C=O</smiles>

14

13 examples

$55-96 \%$ yield $94-99 \%$ ee dr $6: 1$ to $18: 1$
Scheme 5: Preparation of chiral tetrahydrothiophenes using trans-ethyl 4mercapto-2-butenoate as reaction partner of $\alpha, \beta$-unsaturated aldehydes.

Interestingly, the same group disclosed an alternative catalytic, noncovalent activation strategy based on the use of the 
bifunctional amine thiourea catalyst 17 which allowed to perform the "one-pot" thio-Michael-Michael cascade process between 11b and nitroalkenes 15 with high enantio- and diastereoselectivity, producing trisubstituted tetrahydrothiophenes $\mathbf{1 6}$ possessing the nitro functional group and three different stereocentres (Scheme 6). ${ }^{[7]}$<smiles>[R]C=C[N+](=O)[O-]</smiles>

$\mathrm{R}=\mathrm{Ph}, 2,5-\mathrm{Cl}_{2} \mathrm{C}_{6} \mathrm{H}_{3}, 2-\mathrm{ClC}_{6} \mathrm{H}_{4}, 4-\mathrm{FC}_{6} \mathrm{H}_{4}, 2-\mathrm{CF}_{3} \mathrm{C}_{6} \mathrm{H}_{4}$, $3-\mathrm{BrC}_{6} \mathrm{H}_{4}, 4-\mathrm{ClC}_{6} \mathrm{H}_{4}, 4-\mathrm{MeC}_{6} \mathrm{H}_{4,}, 2,3-(\mathrm{OMe})_{2} \mathrm{C}_{6} \mathrm{H}_{3}, 2,4-$ $(\mathrm{OMe})_{2} \mathrm{C}_{6} \mathrm{H}_{3}, 3-\mathrm{MeOC}_{6} \mathrm{H}_{4}$, 4-MeOC ${ }_{6} \mathrm{H}_{4}$, 2-furanyl, 2thienyl, $i \mathrm{Pr}$

Scheme 6: "One-pot" thio-Michael-Michael cascade process between transethyl 4-mercapto-2-butenoate and nitroalkenes for the formation of trisubstituted tetrahydrothiophenes with high enantio- and diastereoselectivity.

In 2012, De Risi and co-workers envisioned the reaction of 1 with cyclohexenone as a straightforward route to the hexahydro-benzothiophen-4-one nucleus (Scheme 7). ${ }^{[8]}$ Indeed, the sulfa-Michael/aldol reaction sequence carried out in DCM with catalytic triethylamine (5 mol \%), proceeded smoothly and lead to the formation in good yield $(75 \%)$ of a $3: 1$ mixture of the diastereomeric hexahydro-benzothiophen-4-ones 18 and 19.<smiles>O=C1C=CCCC1</smiles>
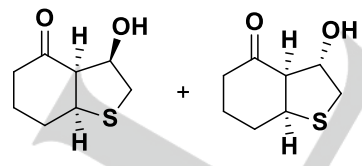

18 $\mathrm{dr}=3: 1$

Scheme 7: Sulfa-Michael/aldol reaction of mercaptoacetaldehyde for the formation of the hexahydro-benzothiophen-4-one scaffold.

In 2014, an efficient, eco-friendly and catalyst-free construction of trisubstituted tetrahydrothiophenes has been accomplished by Song et al. via a sulfa-Michael/aldol (Henry) cascade reaction in water, allowing to obtain a series of tetrahydrothiophene derivatives such as $\mathbf{2 1}$ from a range of chalcones $\mathbf{2 0}$ in good yields (up to $91 \%$ ) and excellent diastereoselectivities (up to $>99: 1$ ) $\left(\right.$ Scheme 8). ${ }^{[9]}$

Very recently, a highly enantioselective cascade sulfaMichael/aldol reaction catalyzed by chiral fluoride generated in situ from catalytic amount of KF binding with Song's oligoEG

catalyst offered a new protocol for the synthesis of trisubstituted tetrahydrothiophenes, obtained in up to $99 \%$ yield, with $d r>20: 1$ and ee up to $98 \%$. $^{[10,11]}$

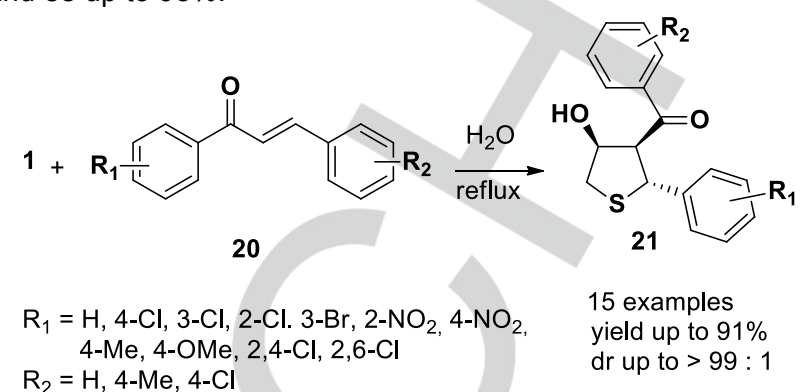

Scheme 8: Synthesis of trisubstituted tetrahydrothiophenes via a highly enantioselective cascade sulfa-Michael/aldol reaction.

Notably, Ramström and co-workers firstly described a nice example of resolution of the thiolane structures created by consecutive thia-Michael and Henry reactions using a combination of Lewis acid and base activation. Thus, the 1,1,3,3-tetramethylguanidine (TMG)/ zinc iodide-catalyzed diastereoselective sulfa-Michael/nitroaldol cascade reaction of trans- $\beta$-methyl- $\beta$-nitrostyrenes 22 with 1 was combined with a lipase-catalyzed kinetic resolution, one diastereoisomer of the racemic tetrahydrothiophenes $\mathbf{2 4}$, present at the equilibrium together 23 , being preferentially acylated by the enzyme to give the product 25 in high ee (Scheme 9). ${ }^{[12][13]}$

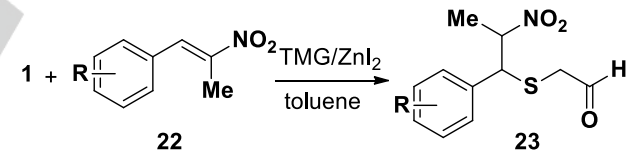

$\mathrm{R}=2,4-\mathrm{OMe}, 3,4-\mathrm{OMe}$

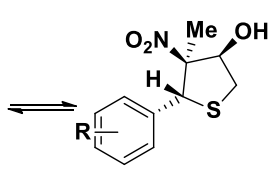

24

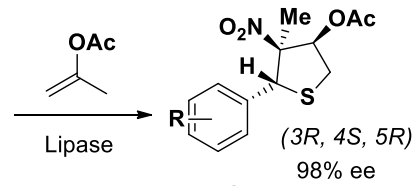

25

Scheme 9: Diastereoselective cascade sulfa-Michael/nitroaldol reaction of trans- $\beta$-methyl- $\beta$-nitrostyrenes and mercaptoacetaldehyde and subsequent lipase-catalyzed kinetic resolution.

The reactivity of mercaptoaldehyde as a dual reactive substrate has been exploited by $\mathrm{Xu}$ and co-workers ${ }^{[14]}$ as the starting move of an efficient synthesis of enantioenriched trisubstituted tetrahydrothiophenes 26 via a bifunctional amino-squaramidecatalyzed domino sulfa-Michael/aldol cascade reaction with chalcones 20 (Scheme 10). 


$$
\text { toluene, } 60^{\circ} \mathrm{C}
$$

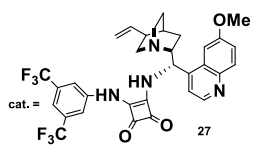

$R=R_{1}=P h ; R=P h, R_{1}=2-M_{e} C_{6} H_{4} ; R=P h, R_{1}=3 M_{e C} H_{4}, R=P h ; R_{1}=3-C_{C} C_{6} H_{4} ; R=P h$, $\mathrm{R}_{1}=4-\mathrm{MeC}_{6} \mathrm{H}_{4} ; \mathrm{R}=\mathrm{Ph}, \mathrm{R}_{1}=4-\mathrm{FC}_{6} \mathrm{H}_{4} ; \mathrm{R}=\mathrm{Ph}, \mathrm{R}_{1}=4-\mathrm{BrC}_{6} \mathrm{H}_{4} ; \mathrm{R}=\mathrm{Ph}, \mathrm{R}_{1}=4-\mathrm{ClC}_{6} \mathrm{H}_{4} ; \mathrm{R}=\mathrm{Ph}$, $\mathrm{R}_{1}=4-\mathrm{MeOC}_{6} \mathrm{H}_{4} ; \mathrm{R}=3-\mathrm{BrC}_{6} \mathrm{H}_{4}, \mathrm{R}_{1}=\mathrm{Ph} ; \mathrm{R}=4-\mathrm{ClC}_{6} \mathrm{H}_{4}, \mathrm{R}_{1}=\mathrm{Ph} ; \mathrm{R}=4-\mathrm{BrC}_{6} \mathrm{H}_{4}, \mathrm{R}_{1}=\mathrm{Ph} ; \mathrm{R}$
$\mathrm{OMeC}_{6} \mathrm{H}_{4}, \mathrm{R}_{1}=\mathrm{Ph} ; \mathrm{R}=4-\mathrm{MeOC}_{6} \mathrm{H}_{4}, \mathrm{R}_{1}=\mathrm{Ph} ; \mathrm{R}=2$-tienyl, $\mathrm{R}_{1}=\mathrm{Ph} ; \mathrm{R}=2$-furyl, $\mathrm{R}_{1}=\mathrm{Ph}$

Scheme 10: Synthesis of enantioenriched trisubstituted tetrahydrothiophenes via amino-squaramide-catalyzed domino sulfaMichael/aldol reactions.

Trisubstituted tetrahydrothiophenes $\mathbf{2 6}$ bearing three contiguous stereogenic centers have been obtained at low catalyst loading in good to excellent yields (71-91\%) and high stereoselectivities (8:1-20:1 dr and $84-97 \%$ ee) in the presence of the cinchonaderived aminosquaramide 27 , its mode of action being authoritatively discussed by Enders and coworkers. ${ }^{[15]} \mathrm{A}$ remarkable temperature effect on the reaction efficiency was observed, and a gram-scale synthesis was also successfully accomplished. The enantioinduction was not influenced by the nature and the position of the substituents on the phenyl ring of chalcones.

The following year, the same group applied a similar organocatalytic domino reaction to the construction of chiral $\mathrm{CF}_{3}$-containing tetrahydrothiophenes 29 by reacting 1 with $\beta$ aryl- $\beta$-trifluoromethylated enones 28 (Scheme 10). ${ }^{[16]}$ The catalytic intermolecular cascade reaction has been carried out in the presence of the same cinchona alkaloid-derived squaramide catalyst 27 . The chiral trifluoromethyl tetrahydrothiophenes $\mathbf{2 9}$ featuring three contiguous stereocenters and a $\mathrm{CF}_{3}$-quaternary carbon center were obtained in yields of up to $87 \%$, diastereoselectivities of up to 9:1 and enantioselectivities of up to $89 \%$.

The easily prepared tertiary amine immobilized on fiber has been shown to act as efficient catalyst for tandem Michaelintramolecular Henry reactions between 1,4-dithiane-2,5-diol 1 and trans- $\beta$-nitrostyrenes affording the corresponding tetrahydrothiophene derivatives 30 and 31 (Scheme 11).$^{[1]}$ Its application to a wide range of trans- $\beta$-nitroalkenes allowed to obtain substituted tetrahydrothiophenes in good to excellent yields $(75-93 \%)$ under mild conditions (with $2.5 \mathrm{~mol} \%$ fiber catalyst at $50{ }^{\circ} \mathrm{C}$ in ethanol for $5 \mathrm{~h}$ ). The fiber catalyst could be reused up to 10 times after simple workup procedure, with only a slight loss in catalytic activity.

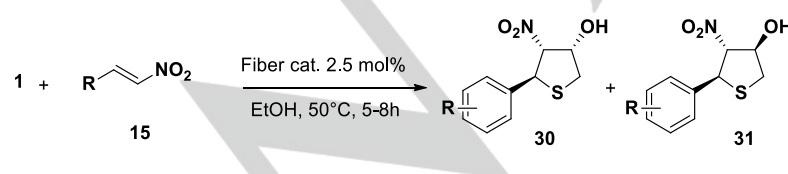

$\mathrm{R}=\mathrm{Ph}, 3-\mathrm{OMeC}_{6} \mathrm{H}_{4} 2-\mathrm{OMeC}_{6} \mathrm{H}_{4} 4-\mathrm{OMeC}_{6} \mathrm{H}_{4} 4-\mathrm{O}_{2} \mathrm{NC}_{6} \mathrm{H}_{4} \quad 16$ examples

$3-\mathrm{O}_{2} \mathrm{NC}_{6} \mathrm{H}_{4}, 4-\mathrm{FC}_{6} \mathrm{H}_{4}, 2-\mathrm{ClC}_{6} \mathrm{H}_{4}, 4-\mathrm{CiC}_{6} \mathrm{H}_{4}, 4-\mathrm{BrC}_{6} \mathrm{H}_{4}$

$2,4-\mathrm{Me}_{2} \mathrm{C}_{6} \mathrm{H}_{3}, 4-\mathrm{CH}=\mathrm{CHNO}_{2}, 2-\mathrm{CF}_{3} \mathrm{C}_{6} \mathrm{H}_{4}$
Scheme 11: Catalyzed tandem Michael-intramolecular Henry reactions between mercaptoacetaldehyde and trans- $\beta$-nitrostyrenes to form tetrahydrothiophene derivatives.

Recently, NHC-catalyzed carba-, sulfa-, and phospha-Michael additions were efficiently accomplished by Hans and co-workers using the readily available and convenient imidazol(in)ium-2carboxylate $\left(\mathrm{NHC} \cdot \mathrm{CO}_{2}\right)$ precatalysts (Scheme 12); however, despite the reaction of 1 with methyl vinyl ketone in the presence of ICy. $\mathrm{CO}_{2} 32(2.5 \mathrm{~mol} \%)$ in THF produced the corresponding tetrahydrothiophene $\mathbf{3 3}$ in excellent yield, the diastereoselectivity remained modest. ${ }^{[18]}$

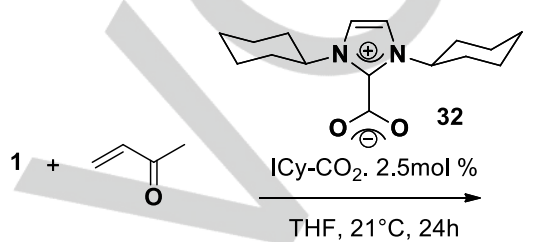<smiles>CC(=O)C1CSCC1O</smiles>

33

$98 \%$ yield $\mathrm{dr}=1.7: 1$

Scheme 12: NHC-catalyzed sulfa-Michael addition for the synthesis of tetrahydrothiophenes.

Knoevenagel condensation of various aromatic and heteroaromatic aldehydes 34 with 3,5-dimethyl-4-nitroisoxazole 35 followed by domino sulfa-1,6-Michael/intramolecular vinylogous Henry reactions between between the derived nitrostyrene derivatives $\mathbf{3 6}$ and $\mathbf{1}$ has been elegantly designed by Kashinath et al. ${ }^{[19]}$ for a rapid synthesis of highly functionalized tetrahydrothiophene (thiolane) derivatives 37 bearing the biologically useful isoxazole nucleus.

The desired products 36 could be obtained with $>95 \%$ yields in 2-2.5 h overall reaction time through a careful choice of base (piperidine, $30 \mathrm{~mol} \%$ ) and solvent (ethanol). (Scheme 13). ${ }^{[19]}$
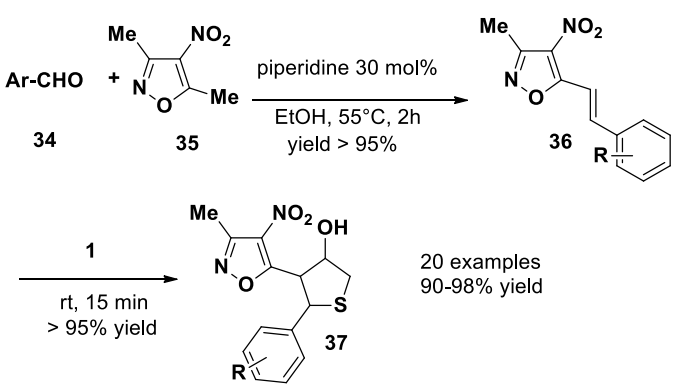

$\mathrm{Ar}=4-\mathrm{MeC}_{6} \mathrm{H}_{4}, 4-\mathrm{MeOC} 6 \mathrm{H} 4,3,4-\mathrm{MeOC}_{6} \mathrm{H}_{3}, 2,5-\mathrm{MeOC}_{6} \mathrm{H}_{3}, 3,4,5-\mathrm{MeOC}_{6} \mathrm{H}_{2}$, 2-HO, 3- $-\mathrm{MeOC}_{6} \mathrm{H}_{3}, 2-\mathrm{HOC}_{6} \mathrm{H}_{4}, 2-n \mathrm{Pr}, 3-\mathrm{HOC}_{6} \mathrm{H}_{3}, 3-\mathrm{NMe}_{2} \mathrm{C}_{6} \mathrm{H}_{4} 3-\mathrm{BrC}_{6} \mathrm{H}_{4}$, $3-\mathrm{ClC}_{6} \mathrm{H}_{4}, 3,4-\mathrm{ClC}_{6} \mathrm{H}_{3}, 2-\mathrm{NO}_{2} \mathrm{C}_{6} \mathrm{H}_{4}, 3-\mathrm{NO}_{2} \mathrm{C}_{6} \mathrm{H}_{4}, 4-\mathrm{NO}_{2} \mathrm{C}_{6} \mathrm{H}_{4}, 1$-naphthyl, 2-thienyl, 4-(1,3-diphenyl)-1 $\mathrm{H}$-pyrazole, 4-[3-(4-chlorophenyl)-1-phenyl-1 $\mathrm{H}$-pyrazole, 3-(4-oxo-4H-1-benzopyran)

Scheme 13: Synthesis of highly functionalized isoxazole-tetrahydrothiophene hybrids. 
In recent years, organic synthesis under continuous-flow conditions has attracted much attention because of its environmental friendliness, efficiency, and safety. Under this condition, the synthesis of $\beta$-nitrostyrene derivatives was efficiently accomplished continuously for at least 100 hours with high selectivity from aromatic aldehydes and nitromethane using readily available amino-functionalized silica gel as the catalyst. In a second step, the $\beta$-nitrostyrene derivatives were reacted with 1 using secondary amine-functionalized, aluminumcontaining MCM-41 packed in column as the catalyst, giving rise to the formation of the desired tetrahydrothiophene in $75-94 \%$ yield during $48 \mathrm{~h}$ (Scheme 14). ${ }^{[20]}$

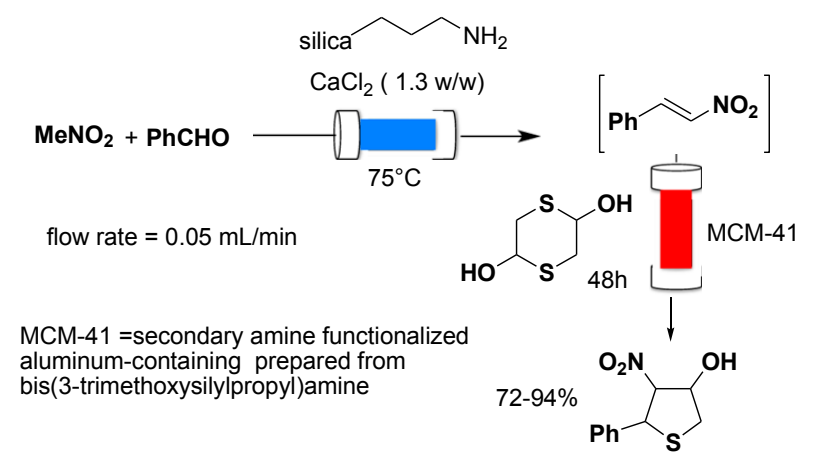

associated to this structurally unique class of molecules frequently found in many natural products and biologically active molecules. A recent review highlighted the versatility of spiro scaffolds in drug discovery owing to their inherent threedimensionality and structural novelty. ${ }^{[22]}$

The development of methods for the stereoselective construction of chiral spirocyclic tetrahydrothiophene derivatives became a topical subject in synthetic chemistry. A variety of spirotetrahydrothiophene scaffolds anchored to different skeletons have been described in a flurry of papers that appeared in the literature in the last four years ${ }^{[24-39]}$ taking advantage of the excellent anellating properties of 1 as well as the derived 4-mercapto-2-butenoates 11a-d in partnership with $\alpha, \beta$-unsaturated carbonyl compounds. These transformations have been very recently reviewed, highlighting the pivotal role of organocatalysis as a powerful and versatile tool for the rapid construction of spirotetrahydrothiophene motifs. ${ }^{[23]}$ The main structures synthetized are listed in the following Scheme 16.

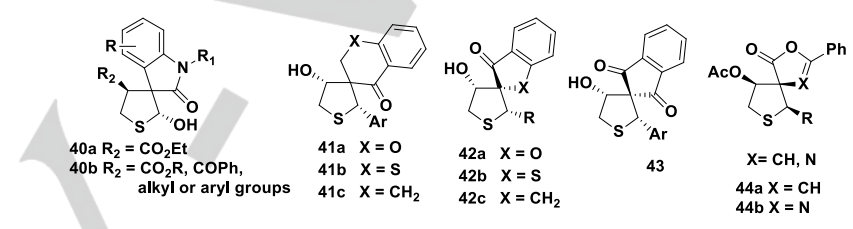

Scheme 14: Formation of trisubstituted tetrahydrothiophenes in flow conditions

Very recently, functionalized tetrahydrothiophenes 39 with quaternary centers with geminal electron withdrawing groups have been efficiently obtained in $80-95 \%$ yields by reaction of 1 with the Knoevenagel condensation products of aldehydes 38 with malononitrile or ethyl cyanoacetate in water $(2 \mathrm{~mL})$ at $50^{\circ} \mathrm{C}$. (Scheme 15). ${ }^{[21]}$

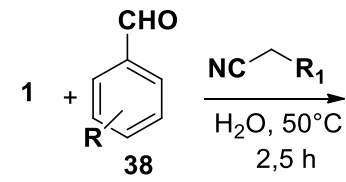<smiles>[R][C@H]1CS[C@@H](c2ccccc2)[C@@]([R])(C#N)[C@@H]1O</smiles>

16 examples

$\mathrm{R}=\mathrm{H}, 4-\mathrm{Me}, 2-\mathrm{OMe}, 3-\mathrm{OMe}, 4-\mathrm{OMe}, 3,4-\mathrm{OMe}$, $3,4,5-\mathrm{OMe}, 4-\mathrm{Br}, 3-\mathrm{NO}_{2}, 2-\mathrm{NO}_{2}$ 1-naphthyl, 2-thienyl, 4-(1,3-diphenyl-)-1H-pyrazole)

$\mathrm{R}_{1}=\mathrm{CN} \quad 80-90 \%$ yield

$\mathrm{R}_{1}=\mathrm{CO}_{2} \mathrm{Et} 85-95 \%$ yield

Scheme 15: Synthesis of functionalized tetrahydrothiophenes with quaternary centers with geminal electron withdrawing groups.

\subsection{Synthesis of spirotetrahydrothiophenes}

In the last years, the synthesis of spiro heterocycles has attracted a great deal of attention owing to the interesting conformational features and wide spectrum of applications

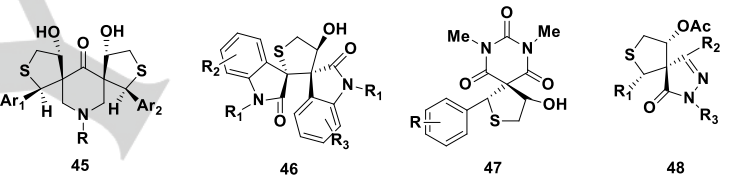

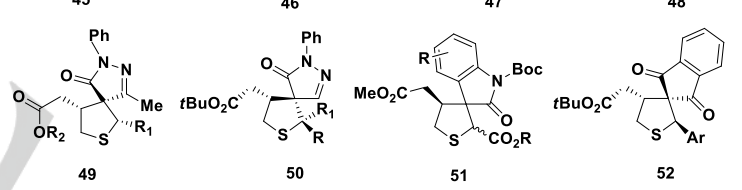

Scheme 16: Chiral spirocyclic tetrahydrothiophene derivatives.

The first synthetic approach to spirocyclic oxyindole fusedtetrahydrothiophene derivatives exploiting the reactivity of 1 as anellating agent concerned the synthesis of tetrahydrothiophene-fused spirooxindoles $\mathbf{4 0 a}{ }^{[24]}$ This operation has been achieved through domino thia-Michael/aldol reaction between 1 and 3-alkenyloxindoles catalyzed by the organoCinchona-based squaramide $27,{ }^{[15]}$ the reaction scope being limited to the strong electron-deficient ester group of substituted 3-alkenyloxindoles. Later, use of chiral N,N'-dioxide-nickel(II) complex system ${ }^{[25]}$ as the catalyst allowed to extend this approach to the preparation of a broad spectrum of enantioenriched spirocyclic oxindole-fused tetrahydrothiophene compounds $40 \mathrm{~b}$ (56-97\% yields, $90-98 \%$ ee, 8:1 to $>19: 1 \mathrm{dr}$ ). Spirocyclic tetrahydrothiophene chromanone derivatives 41a and 41c, featuring three contiguous stereocenters, have been obtained in high to excellent yields (up to 99\%) and with high enantioselectivities (up to $92 \%$ ee) using the readily available bifunctional squaramide organocatalyst 27 while 41 b and $41 c$ have been prepared with moderate to good enantioselectivities employing readily available chiral quaternary ammonium salts as 
organocatalysts. ${ }^{[26,27]} \quad$ Very recently, spirocyclic tetrahydrothiophene chromanone derivatives 41c have been enantioselectively obtained with Song's chiral oligoEG as a cation binding catalyst and catalytic amount of KF. ${ }^{[11]}$ Moreover, 41a has been conveniently obtained in a diastereoselective fashion in the presence of triethylamine. ${ }^{[28]}$

Spirocyclic tetrahydrothiophene derivative $42 a$, bearing a benzofuran-3(2H)-one, has been prepared enantioselectively applying the bifunctional catalyst 27 and by using Song's chiral fluoride complex. ${ }^{[11,29]}$ Replacement of the benzofuran-3(2H)one with the benzothiophen-3(2H)-one moiety produced $42 \mathrm{~b}$ with moderate enantioselectivity. A library of 2'-(aryl)-4'-hydroxy4',5'-dihydro-2' $\mathrm{H}$-spiro[indene-2,3'-thiophen]-1(3H)-ones $42 \mathrm{c}$ has been obtained stereoselectively through domino reactions of $(E)$ 2-(aryl)-2,3-dihydro-1H-inden-1-ones and 1 in the presence of triethylamine in water. ${ }^{[30]}$

Enders and co-workers described the synthesis of tetrahydrothiophene bearing spiro indane-1,3-dione derivatives 43 in excellent yields and good stereoselectivities through a squaramide-catalyzed sulfa-Michael/aldol domino reaction, ${ }^{[31]}$ while Hejmanowska and Albrecht reported the preparation spirocyclic tetrahydrothiophenes bearing either a butenolide or an azlactone moiety (44a and 44b) using chiral bases derived from cinchona alkaloids as the catalyst. ${ }^{[32]}$ A library of novel bisspiropiperidone-tetrahydrothiophene hybrid heterocycles $\mathbf{4 5}$ has been synthesized via pseudo-three-component domino reaction of $\quad(3 E, 5 E)-3,5$-bis(arylidene)-1-methyl/benzylpiperidin-4-ones and 1 in the presence of triethylamine. ${ }^{[3]}$ Chiral bisspirooxindole tetrahydrothiophenes $\mathbf{4 6}$ with vicinal quaternary spirocenters has been built up through a cinchona alkaloid catalyzed enantioselective sulfa-Michael/aldol cascade reaction of isoindigos. ${ }^{[34]}$

Moreover, a green and efficient one-pot reaction of aldehydes with barbituric acid or malononitrile and 1 have been developed for the synthesis of quaternary-centered spirobarbituratetetrahydrothiophene hybrids $\mathbf{4 7}$ via Knoevenagel condensation, 1,4-thia-Michael and intramolecular aldol reactions using "on water" concept under catalyst-free conditions. ${ }^{[21]}$

Michael/Michael reaction, one of the most powerful and reliable tools for the stereocontrolled assembly of molecular architectures, has been used as an efficient method for the construction of chiral spirotetrahydrothiophene derivatives. In 2016, spiro[pyrazolone-4,3'-tetrahydrothiophene] derivatives 48 and 49 have been produced in moderate to excellent yelds and diastereomeric ratios (up to $98 \%$ yield and $>20: 1 \mathrm{dr}$ ) via sulfaMichael/aldol domino reactions catalyzed by $\mathrm{N}, \mathrm{N}-$ diisopropylethylamine in methylene chloride or 1,4diazabicyclo[2.2.2] octane (DABCO) in toluene at $0{ }^{\circ} \mathrm{C}$ using 1 and trans-ethyl 4-mercapto-2-butenoate $11 \mathrm{~b}$ as partners of various arylidenepyrazolones. ${ }^{[35,36]}$ One year later, Lattanzi and co-workers were able to obtain spirocyclic compounds $\mathbf{5 0}$ in good yields and fairly good diastereo- and enantioselectivities by reacting $\alpha, \beta$-unsaturated pyrazolones and tert-butyl $(E)-4-$ mercapto-2-butenoate $11 \mathrm{c}$ in the presence of a readily available secondary amine thiourea derived from $(R, R)-1,2-$ diphenylethylenediamine. ${ }^{[37]}$

Furthermore, the reactions between trans-ethyl 4-mercapto-2butenoate 11b as the reaction partner of methyleneindolinones provided the spirooxindole-tetrahydrothiophenes $\mathbf{5 1}$ in high yields and excellent enantioselectivities. ${ }^{[38]} \mathrm{A}$ similar strategy has been applied to prepare chiral spiro[indane-1,3-dionetetrahydrothiophene] skeletons $\mathbf{5 2}$ which have been constructed in good yields (75-99\%) with high enantioselectivities (89-99\% ee) and diastereoselectivities by reacting 2-arylidene-1,3- indanediones and 4-mercapto-2-butenoate 11c in the presence of a tertiary amine-thiourea organocatalyst. ${ }^{[39]}$

\subsection{Synthesis of Dihydrothiophenes}

Dihydrothiophenes and their derivatives are key components present in many natural products, bioactive compounds, and synthetic intermediates, and their oxidation or reduction smoothly affords thiophenes or tetrahydrothiophenes, respectively. ${ }^{[1,2]}$ A stereoselective synthesis of dihydrothiophenes has been accomplished through organocatalytic asymmetric domino sulfa-Michael/aldol condensation reactions between 1 and cinnamaldehydes 53 in the presence of (S)-diphenylprolinol TMS ether and bile acid derivatives, giving rise to the formation of 4,5-dihydrothiophene2-carbaldehydes $\mathbf{5 4}$ in moderate to good yields and enantioselectivities (Scheme 17). ${ }^{[40]}$

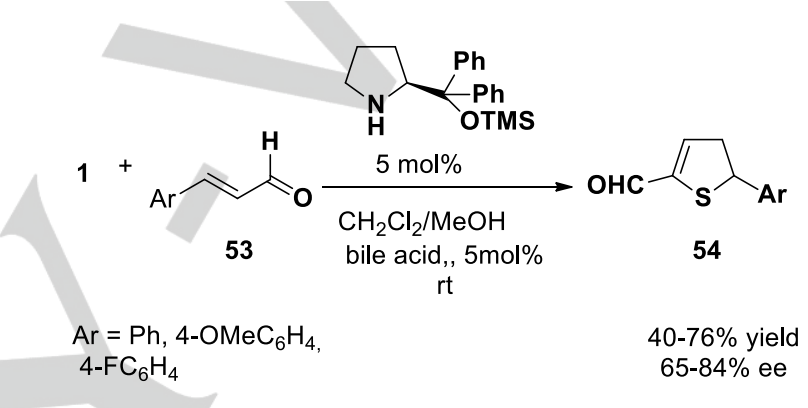

Scheme 17: (S)-diphenylprolinol TMS ether organocatalytic asymmetric domino sulfa-Michael/aldol condensation between 1 and cinnamaldehydes for the synthesis of dihydrothipphenes.

In 2010, Xu and co-workers developed an organocatalytic domino thia-Michael/aldol condensation reaction between $\alpha, \beta-$ unsaturated aldehydes 55 and 1 catalyzed by chiral diphenylprolinol trimethylsilyl ether to produce chiral dihydrothiophenes $\mathbf{5 6}$ in high yields (up to 90\%) and excellent enantioselectivities (up to>99\% ee) (Scheme 18). ${ }^{[41]}$
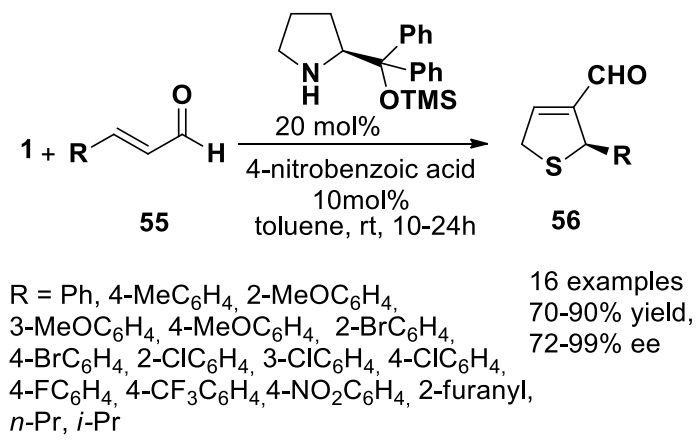

Scheme 18: Organocatalytic domino thia-Michael/aldol condensation of unsaturated aldehydes with 1 to produce chiral dihydrothiophenes.

De Risi and co-workers found that the preparation of the known enantiopure (or enantioenriched) 2,5-dihydrothiophene-3 
carbaldehydes 56 described by $\mathrm{Xu}$ and co-workers required a careful re-examination of the experimental conditions, being unable to obtain the required compounds following the reported directions. ${ }^{[42,43]}$ Thus, the reaction between 1 and cinnamaldehyde was carried out in DCM instead of toluene at $40{ }^{\circ} \mathrm{C}$ for $2 \mathrm{~h}$, under inert atmosphere and in the presence of the commercially available chiral diphenylprolinol trimethylsilyl ether as catalyst $(20 \mathrm{~mol} \%)$ and benzoic acid $(10 \mathrm{~mol} \%)$ as additive. More recently, the catalytic versatility of pepsin has been cleverly applied to a promiscuous pepsin-catalyzed asymmetric domino thia-Michael/aldol condensation reaction of aromatic, heteroaromatic, and aliphatic $\alpha, \beta$-unsaturated aldehydes with 1 in buffered acetonitrile allowing to obtain the corresponding functionalized chiral dihydrothiophenes with $40-84 \%$ ee without any additive. ${ }^{[44]}$

\subsection{Synthesis of Thiophenes}

Thiophene is a privileged five-membered heterocycle present as a subunit in numerous natural products and pharmaceuticals, and its numerous derivatives have emerged as a class of important heterocycles, which not only exhibit a variety of biological and medical properties, but are also widely used in material science and organic synthesis as versatile intermediates. $^{[1,2]}$

In 1991, Gooding and Beard described a short pathway to Ticlopidine 59 based on the condensation of 1 with $\mathrm{N}$-(2chlorobenzyl)-4-piperidone $\mathbf{5 7}$ in the presence of lithium diisopropylamide. Subsequent acid treatment of the fused dihydroxytetrahydrothiophene intermediate $\mathbf{5 8}$ promoted dehydration to the required thiophene ring system in $58 \%$ overall yield (Scheme 19). ${ }^{[45]}$<smiles>O=C1CCN(Cc2ccccc2Cl)CC1</smiles><smiles>O=C(O)[C@H](C1SC2(O)CCN(Cc3ccccc3Cl)CC2C1O)C(F)(F)F</smiles>

$$
\begin{aligned}
& \underset{\mathrm{H}_{2} \mathrm{SO}_{4} \text { conc. }}{\stackrel{0}{ } \mathrm{C} \text { to reflux }} \\
& \underset{58 \% \text { overall yield }}{\longrightarrow}
\end{aligned}
$$<smiles>Clc1ccccc1CN1CCc2sccc2C1</smiles>

Scheme 19: Condensation of 1 with $N$-(2-chlorobenzyl)-4-piperidone and subsequent reaction for the synthesis of Ticlopidine $\mathbf{5 9}$.

A new approach to form 3-nitro-2-substituted thiophenes 61 has been developed which involved dehydration and subsequent oxidative aromatization under microwave irradiation of the corresponding tetrahydrothiophenes $\mathbf{6 0}$, obtained as a mixture of diastereoisomers in high yields by tandem conjugateaddition/nitroaldol ring closure reaction (Scheme 20). ${ }^{[4]}$ A simple workup procedure removes the requirement for purification by chromatography in most cases. ${ }^{[46]}$ More recently, the same research group has described a one-pot approach to the synthesis of 3-nitrothiophene and 3-nitro-2-substituted thiophenes: they optimised the dehydration and oxidation reactions employing the tetrahydrothiophene derivatives $\mathbf{6 0}$, which were obtained in $99 \%$ yield by reaction of the commercially available $\beta$-nitrostyrene with 1 in the presence of $25 \% \mathrm{Et}_{3} \mathrm{~N}$ in DCM solution. ${ }^{[4,47]}$ Nonetheless, conversion to the desired thiophene has been achieved in $98 \%$ yield after heating at reflux for $24 \mathrm{~h}$ in the presence of silica gel (8 equiv w/w) and using DDQ (4 equiv) and molecular sieves (4 equiv w/w).

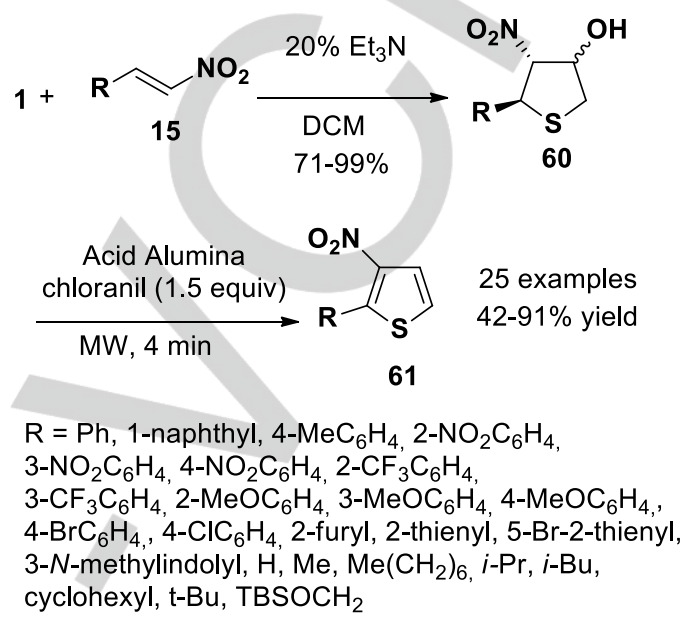

Scheme 20: One-pot approach to the synthesis of 3-nitrothiophene and 3nitro-2-substituted thiophenes.

A triethylamine-catalyzed [3+2] cycloaddition of 1 with aromatic and aliphatic ynals 62 has been efficiently used to synthesize 3aldehyde-2-substituted thiophenes 63 in one step and high yields (Scheme 21). ${ }^{[48]}$ Triethylamine was identified as the best catalyst for this transformation, the yields decreasing to $70-80 \%$ in the presence of other organic bases such as DEA, DIPEA and pyridine. The reaction showed good tolerance for aromatic ynals, electronwithdrawing or electrondonating groups in different positions of the aromatic aldehyde.

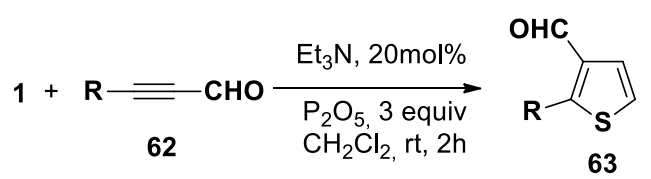

$\begin{aligned} \mathrm{R}=\mathrm{Ph}, 4-\mathrm{FC}_{6} \mathrm{H}_{4}, 4-\mathrm{ClC}_{6} \mathrm{H}_{4}, 4-\mathrm{BrC}_{6} \mathrm{H}_{4}, & 12 \text { examples } \\ 4-\mathrm{MeC}_{6} \mathrm{H}_{4} 4-\mathrm{EtC}_{6} \mathrm{H}_{4} 4-\mathrm{OMeC}_{6} \mathrm{H}_{4}, & 63-86 \% \text { yield }\end{aligned}$ 4-t- $-\mathrm{BuC}_{6} \mathrm{H}_{4} ; 2-\mathrm{ClC}_{6} \mathrm{H}_{4} ; 2$-thienyl, $n$-Bu, $\mathrm{SiEt}_{3}$

Scheme 21: Synthesis of 3-aldehyde-2-substituted thiophenes via [3+2] cycloaddition of 1 with aromatic and aliphatic ynals.

Notably, this sequence could be extended to other $\alpha, \beta$ unsaturated substrates, furnishing thiophene derivatives containing various functional groups such as ester and ketone groups at the 3-position of the thiophene ring.

Three examples of employment of 1 as a two-atom component in the thiophene synthesis have been reported in the literature. 
This strategy has been firstly devised by Sathishkannan and Srinivasan for the synthesis of tetrasubstituted thiophenes $\mathbf{6 6}$ through $\mathrm{AlCl}_{3}$-mediated [3+3] annulation of 1,3-zwitterionic intermediates - derived from the cyclopropanes 64 - with in situ generated mercaptoacetaldehyde, followed by DBU-induced rearrangement of the resulting tetrahydrothiopyranols $\mathbf{6 5}$, providing the target thiophenes in $55-82 \%$ yields (Scheme 22). ${ }^{[49,50]}$

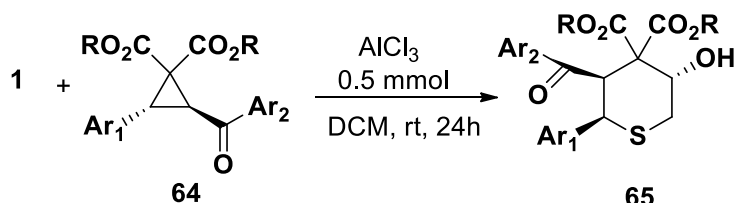

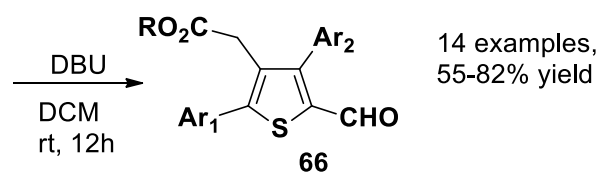

$\mathrm{R}=\mathrm{Me}, \mathrm{Et} ; \mathrm{Ar}_{1}=\mathrm{Ph} .4-\mathrm{MeC}_{6} \mathrm{H}_{4}, 4-\mathrm{ClC}_{6} \mathrm{H}_{4}, 3-\mathrm{FC}_{6} \mathrm{H}_{4}$, $4-\mathrm{OMeC}_{6} \mathrm{H}_{4}, 4-\mathrm{NO}_{2} \mathrm{C}_{6} \mathrm{H}_{4} ; \mathrm{Ar}_{2}=\mathrm{Ph}, 4-\mathrm{MeC}_{6} \mathrm{H}_{4}$, 4- $\mathrm{ClC}_{6} \mathrm{H}_{4}, 4-\mathrm{OMeC}_{6} \mathrm{H}_{4} ; 2$-thienyl

Scheme 22: Employment of $\mathbf{1}$ as a two-atom component in the thiophene synthesis.

More recently (Scheme 23), the same research group described the preparation of tetrasubstituted thiophenes 68 from 1,3-enynes $\mathbf{6 7}$ and $\mathbf{1}$ using DABCO at room temperature, in a domino reaction sequence via a Michael addition, 5-exo-dig carboannulation, and oxidation under air. ${ }^{[51]}$ The broad substrate scope and mild reaction conditions are significant and practical features, but the main advantages of this sequence are the direct introduction of aldehyde and nitro/keto/ester functionalities in the thiophene ring under metal-free and mild conditions.

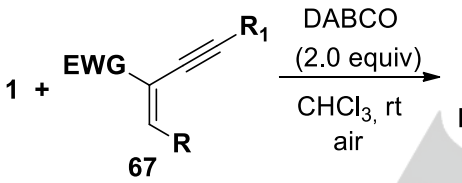

$\mathrm{EWG}=\mathrm{NO}_{2}, \mathrm{CO}_{2} \mathrm{Et}, \mathrm{COPh}$,

$\mathrm{R}=\mathrm{R}_{1}=\mathrm{Ph} ; \mathrm{R}=\mathrm{Ph}, \mathrm{R}_{1}=4-\mathrm{ClC}_{6} \mathrm{H}_{4}$

$\mathrm{R}=\mathrm{Ph}, \mathrm{R}_{1}=3,4-\mathrm{MeC}_{6} \mathrm{H}_{3} ; \mathrm{R}=\mathrm{Ph}, \mathrm{R}_{1}=3,5-\mathrm{MeC}_{6} \mathrm{H}_{3} ;$

$\mathrm{R}=\mathrm{Ph}, \mathrm{R}_{1}=4-\mathrm{OMeC}_{6} \mathrm{H}_{4} ; \mathrm{R}=\mathrm{Ph}, \mathrm{R}_{1}=1$-naphthyl;

$\mathrm{R}=\mathrm{Ph}, \mathrm{R}_{1}=$ cyclopropyl; $\mathrm{R}=2-\mathrm{MeC}_{6} \mathrm{H}_{4}, \mathrm{R}_{1}=\mathrm{Ph}$;

$\mathrm{R}=3 \mathrm{MeC}_{6} \mathrm{H}_{4}, \mathrm{R}_{1}=\mathrm{Ph} ; \mathrm{R}=4-\mathrm{MeC}_{6} \mathrm{H}_{4}, \mathrm{R}_{1}=\mathrm{Ph}$;

$\mathrm{R}=4-\mathrm{FC}_{6} \mathrm{H}_{4}, \mathrm{R}_{1}=\mathrm{Ph} ; \mathrm{R}=4-\mathrm{OMeC}_{6} \mathrm{H}_{4}, \mathrm{R}_{1}=\mathrm{Ph}$;

$\mathrm{R}=1$-naphthyl, $\mathrm{R}_{1}=\mathrm{Ph}$

Scheme 23: Obtainment of tetrasubstituted thiophenes from 1,3-enynes $\mathbf{6 7}$ and mercaptoacetaldehyde

In the same year, the amine-catalyzed cascade [3+2] annulation of $\beta^{\prime}$-acetoxy allenoates 69 and 1 - used here as the bisnucleophile partner - followed by oxidative aromatization allowed to obtain fully substituted thiophene-2carbaldehydes 70 (Scheme 24). ${ }^{[52]}$

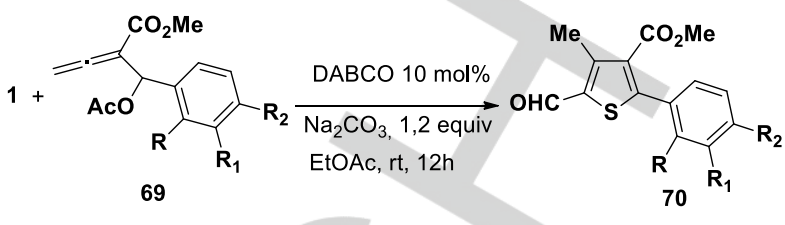

$\mathrm{R}=\mathrm{R}_{1}=\mathrm{R}_{2}=\mathrm{H}$

$\mathrm{R}=\mathrm{R}_{1}=\mathrm{H}, \mathrm{R}_{2}=\mathrm{OMe}, \mathrm{Me}, \mathrm{iPr}, \mathrm{Cl}, \mathrm{Br}, \mathrm{F}$

$\mathrm{R}=\mathrm{R}_{2}=\mathrm{H}, \mathrm{R}_{1}=\mathrm{Br}, \mathrm{NO}_{2}$;

$\mathrm{R}=\mathrm{R}_{2}=\mathrm{Cl}, \mathrm{R}_{1}=\mathrm{H}$

$\mathrm{R}=\mathrm{R}_{2}=\mathrm{Me}, \mathrm{R}_{1}=\mathrm{H}$

Scheme 24: Synthesis of thiophene-2-carbaldehydes.

Even more recently, the reaction of $\alpha$-oxoketene dithioacetals 71 with 1 in the presence of anhydrous potassium carbonate in boiling ethanol has been conveniently utilized to produce the corresponding 2-(methylthio)-3-aroyl/heteroaroyl thiophenes 72 in $55-70 \%$ overall yields (Scheme 25$).{ }^{[53]}$

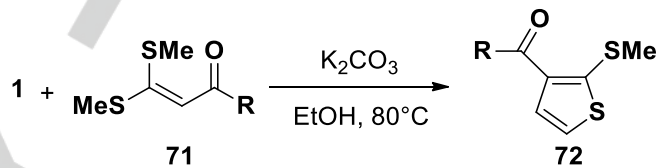

13 examples $25-70 \%$ yield

$\mathrm{R}=\mathrm{Ph}, 4-\mathrm{MeC}_{6} \mathrm{H}_{4}, 4-\mathrm{MeOC}_{6} \mathrm{H}_{4}, 3,4-\mathrm{MeOC}_{6} \mathrm{H}_{3}$, 2,4- $\mathrm{MeOC}_{6} \mathrm{H}_{3}, 4-\mathrm{FC}_{6} \mathrm{H}_{4}, 4-\mathrm{ClC}_{6} \mathrm{H}_{4}, 4-\mathrm{BrC}_{6} \mathrm{H}_{4}$ 1-naphthyl, 2-naphthyl, 2-pyridyl, 2-thienyl, 2-furanyl

Scheme 25: Synthesis of 2-(methylthio)-3-aroyl/heteroaroyl thiophenes from $\alpha$ oxoketene dithioacetals and 1.

The chemistry of 2-aminothiophenes is arguably one of the most extensive and dynamic field of thiophene research, ${ }^{[54]}$ the most convergent and well-established classical approach for their preparation being Gewald's reaction, a multicomponent condensation of $\alpha$-methylene carbonyl compound with $\alpha$-acetonitrile and elemental sulfur. ${ }^{[55]}$ The original protocol has been widely modified since its publication by varying the reaction components and catalysts, the availability of reagents and the mild reaction conditions all contributing to the versatility of this reaction. In addition, microwave and ultrasonic irradiation have also been used to promote the Gewald reaction. ${ }^{[56]}$ The air-stable, readily available 1 has been reported as convenient coupling partner as it represents a suitable substitute for both the carbonyl and sulfur partners, being the precondensation product of acetaldehyde and sulfur. Dumattre and Dodic obtained 2aminothiophene-3-carboxamide in $62 \%$ yield by reaction of thioacetaldehyde dimer with cyanoacetamide at $70{ }^{\circ} \mathrm{C}$ for 2 h. ${ }^{[57]}$ This procedure was also used by Gutschow and Neumann in their synthesis of thieno[1,3]oxazin-4-ones as inhibitors of human leucocyte elastase. ${ }^{[58]}$ In 2007, Hesse and co-workers described the expeditious synthesis of 2- 
aminothiophene-3-carboxylic acid derivatives, which were obtained in two minutes under microwave irradiation and conveniently used for the synthesis of 3H-thieno[2,3d]pyrimidin-4-one derivatives (Scheme 26). ${ }^{[59]}$ A few years later, a $\mathrm{N}$-methylpiperazine-functionalized polyacrylonitrile fiber was used to catalyze the Gewald reaction between 1 and activated nitriles 73 , affording 3-substituted-2-aminothiophenes 74 in good to excellent yields $(65-91 \%)$ (Scheme 26). ${ }^{[60]}$ A low catalyst loading of $8.0 \mathrm{~mol} \%$, simple procedure, high yields, recyclability and reusability of up to 10 times with minimal loss of catalytic activity, are all attractive features of this fiber catalyst. An extension to the Gewald reaction's scope has also allowed to obtain 3-acetyl-2-aminothiophene using cyanoacetone as partner of the $\alpha$-mercaptoaldehyde. ${ }^{[61]}$

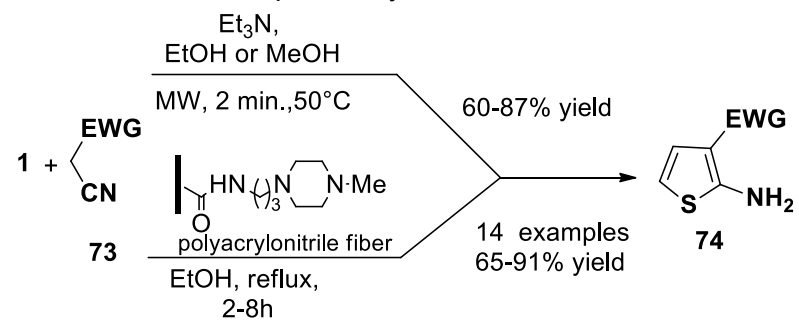

$\mathrm{EWG}=\mathrm{CO}_{2} \mathrm{Et}, \mathrm{CN}, \mathrm{CONH}_{2} \mathrm{CONHAr}$, $\mathrm{COAr}, \mathrm{CO} \mathrm{Bu}, \mathrm{CO}_{2}$-thienyl, $\mathrm{CO}_{2}$-furanyl, $\mathrm{CO}_{2}$ naphthyl, $\mathrm{SO}_{2} \mathrm{Ar}$

Scheme 26: Gewald reaction of mercaptoacetaldehyde for the synthesis of 3electrowithdrawing-2-aminothiophene.

An attractive protocol has also been introduced for the preparation of 3,5-disubstituted-4-aminothiophene-2carbaldehydes 76 by reacting vinyl azides 75 and 1 , allowing the generation of the desired products in a simple, highly efficient and eco-friendly direct synthesis (Scheme 27). ${ }^{[2]}$

$$
\begin{aligned}
& 1+\underset{N_{3}}{\stackrel{\mathrm{K}_{2} \mathrm{CO}_{3}, 1.2 \mathrm{mmol}}{\mathrm{DMF}, 40^{\circ} \mathrm{C}, 4 \mathrm{~h}}} \\
& 75 \\
& \mathrm{R}_{1}=4-\mathrm{ClC}_{6} \mathrm{H}_{4}, 4-\mathrm{O}_{2} \mathrm{NC}_{6} \mathrm{H}_{4}, 4-\mathrm{MeOC}_{6} \mathrm{H}_{4} \text {, } \\
& 4-\mathrm{MeC}_{6} \mathrm{H}_{4}, \mathrm{Ph}, t-\mathrm{Bu} \text {, OEt } \\
& \mathrm{R}_{2}=\mathrm{Ph}, 4-\mathrm{MeC}_{6} \mathrm{H}_{4,}, 4-\mathrm{FC}_{6} \mathrm{H}_{4}, 4-\mathrm{MeOC}_{6} \mathrm{H}_{4} \text {, } \\
& \text { 2- } \mathrm{BrC}_{6} \mathrm{H}_{4}, 3-\mathrm{BrC}_{6} \mathrm{H}_{4,}, 4-\mathrm{BrC}_{6} \mathrm{H}_{4,} \text {, 2-pyridyl, } \\
& \text { 2-furyl, } i \text {-Pr }
\end{aligned}
$$

\section{6 examples}

Scheme 27: Preparation of 3,5-disubstituted-4-aminothiophene-2carbaldehydes by reaction of vinyl azides and $\mathbf{1}$.

A number of 2,3-thienoimides $\mathbf{7 8}$ has been obtained in good to high yields through a formal [3+2] annulation reaction of 1 and $\mathrm{N}$-substituted imides 77 through a one-pot metal-free strategy (Scheme 28). ${ }^{[63]}$ A wide range of $\mathrm{N}$-substituted imides were investigated and all reactions proceeded smoothly, providing the corresponding 2,3-thienoimides in good yields (67-85\%), with the electronic nature and position of the substituents on the aryl ring of the starting imides having no obvious influence on the formation of the desired product.
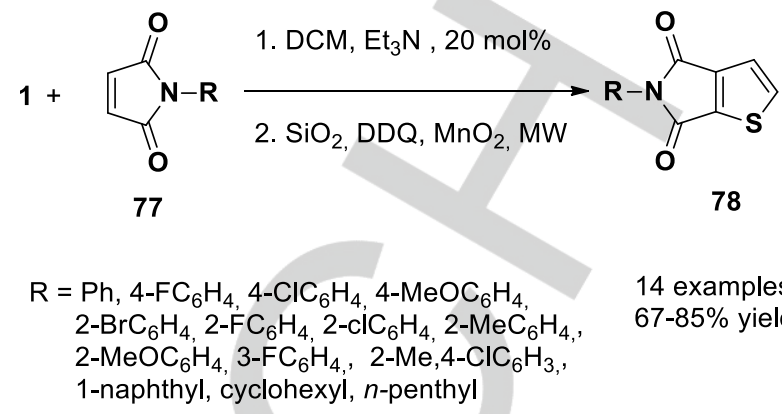

14 examples $67-85 \%$ yield

Scheme 28: Formal [3+2] annulation reaction of 1 and $\mathrm{N}$-substituted imides for the synthesis of 2,3 -thienoimides.

The reaction of trans-2-aryl-3-nitrocyclopropane-1,1dicarboxylates 79 and 1 has been conveniently utilized by Selvi and co-workers (Scheme 29). ${ }^{[50]}$ to prepare 2,3-disubstituted thiophenes 81. The two-step synthesis involved the in situ formation of aroylmethylidene malonates through ring-opening of nitrocyclopropane dicarboxylates $\mathbf{7 9}$ by action of boron trifluoride etherate followed by rearrangement and a Nef reaction. The formation of tetrahydrothiophenes $\mathbf{8 0}$ took subsequently place via tandem thiol-Michael addition/aldol reaction by addition of 1 and triethylamine to the same flask. The derived tetrahydrothiophenes $\mathbf{8 0}$ eventually underwent dehydration and monodecarbethoxylation to the required 2,3-disubstituted thiophenes $\mathbf{8 1}$ upon treatment with $p$-toluenesulphonic acid.<smiles>CCOC(=O)C1(C(=O)OCC)C([17O])[13C]1([O-])OCC</smiles>

79
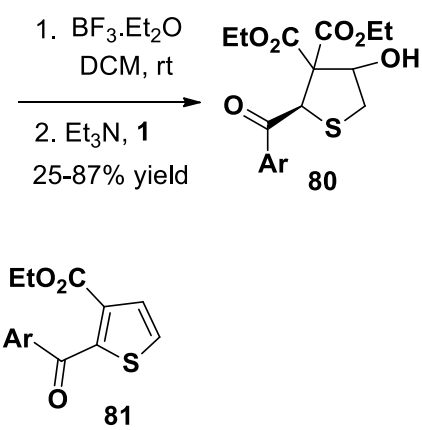

Scheme 29: Two-step synthesis of 2,3-disubstituted thiophenes from trans-2aryl-3-nitrocyclopropane-1,1-dicarboxylates and 1.

Kumar and co-workers reported the reaction of $\alpha$-nitroketene $N, S$-aryl/alkylaminoacetals 82 with 1 in the presence of $\mathrm{K}_{2} \mathrm{CO}_{3}$ in refluxing ethanol as a way for the formation of 3-nitro- $\mathrm{N}$ aryl/alkylthiophen-2-amines $\mathbf{8 3}$ in good yields; it is worth noting that this efficient protocol generates two carbon-carbon bonds in a single operation (Scheme 30$).{ }^{[64]}$ 


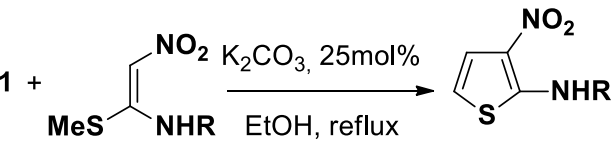

$$
\begin{aligned}
& 82
\end{aligned}
$$

$\mathrm{R}=4-\mathrm{FC}_{6} \mathrm{H}_{4}, 4-\mathrm{ClC}_{6} \mathrm{H}_{4}, 4-\mathrm{BrC}_{6} \mathrm{H}_{4}$ 4- $\mathrm{IC}_{6} \mathrm{H}_{4}, \mathrm{Ph}, 4-\mathrm{MeC}_{6} \mathrm{H}_{4}, 4-\mathrm{EtC}_{6} \mathrm{H}_{4}$

26 examples $82-98 \%$ yield

4- $-\mathrm{PrC}_{6} \mathrm{H}_{4}, 4-\mathrm{MeOC}_{6} \mathrm{H}_{4}, 2-\mathrm{MeC}_{6} \mathrm{H}_{4}$,

2- $\mathrm{MeOC}_{6} \mathrm{H}_{4}, 3-\mathrm{FC}_{6} \mathrm{H}_{4}, 3 \mathrm{ClC}_{6} \mathrm{H}_{4}, 3-\mathrm{BrC}_{6} \mathrm{H}_{4}$,

$3-\mathrm{F}_{3} \mathrm{CC}_{6} \mathrm{H}_{4}, 3-\mathrm{MeC}_{6} \mathrm{H}_{4}, 3-\mathrm{MeOC}_{6} \mathrm{H}_{4}$

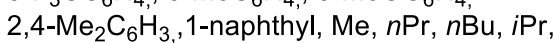
cyclopropyl, cyclohexyl, $\mathrm{Bn},(R)-$ - $-\mathrm{MeBn}$

Scheme 30: Reaction of a-nitroketene N,S-aryl/alkylaminoacetals with 1 for the formation of 3-nitro-N-aryl/alkylthiophen-2-amines.

A concise and regioselective approach for the synthesis of 2,3-disubstituted thiophene derivatives $\mathbf{8 6}$ relied on the reaction of alkynones $\mathbf{8 4}$ - prepared by Sonogashira crosscoupling reaction of readily available acyl chlorides and terminal acetylene derivatives - with in situ-generated 2mercaptoacetaldehyde in the presence of $\mathrm{Et}_{3} \mathrm{~N}$ followed by treatment with silica gel or hydrogen chloride (Scheme 31). ${ }^{[65]}$ The crude 2,3-disubstituted dihydrothiophene derivatives intermediates $\mathbf{8 5}$ are obtained in good to excellent yields and underwent slow dehydration upon standing in chloroform. Final chromatography using silica gel or treatment with acid completed dehydration to the desired thiophene derivatives $\mathbf{8 6}$.
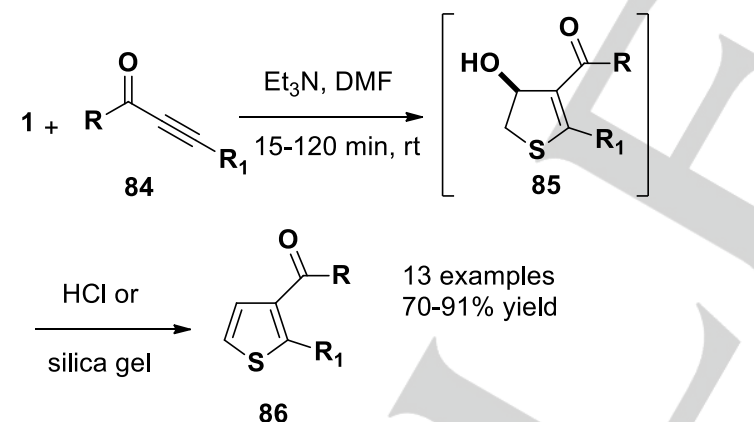

$\mathrm{R}=\mathrm{Me}, t-\mathrm{Bu}, \mathrm{Ph}, 4-\mathrm{MeC}_{6} \mathrm{H}_{4}, 4-\mathrm{NO}_{2} \mathrm{C}_{6} \mathrm{H}_{4}$ 2-naphthyl, 2-furanyl, 2-pyrrolyl, 2-thienyl $\mathrm{R}_{1}=\mathrm{Ph}, n-\mathrm{Bu}, \mathrm{TMS}$,

Scheme 31: Synthesis of 2,3-disubstituted thiophenes by reaction of alkynones and mercaptoacetaldehyde.

Recently, the optically active thiophene derivative 91 has been efficiently obtained by reaction of the $(R)$-derived desymmetrized compound 90 with mercaptoacetaldehyde in the presence of catalytic amount of DABCO, followed by the addition of 1 equivalent of $p$-TsOH (Scheme 32). ${ }^{[6]}$ Compound 90 was previously obtained after the asymmetric desymmetrization of meso-epoxide 88 - derived from cyclopentene-1,3-diones - with 2-mercaptobenzothiazoles 89 through a thiolysis/elimination sequence in the presence of the the chiral Dy(III)/N, $N^{\prime}$-dioxide complex 87.

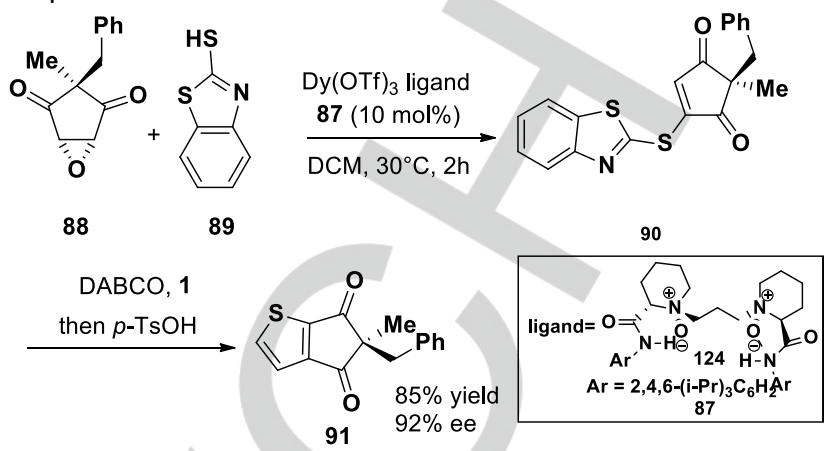

Scheme 32: Desymmetrization of meso-epoxides with 2mercaptobenzothiazoles for the obtainment of optically active thiophene derivatives.

The formation of the thiophene moiety in $\mathbf{9 1}$ results from a basepromoted sulfa-Michael addition/aldol/elimination reaction sequence followed by subsequent acid-promoted aromatization, in which the benzothiazole thioether group served as leaving group. Notably, this reaction could be performed in one pot, affording the thiophene derivative in $85 \%$ yield without loss in the enantiomeric excess.

Very recently, Chittimalla and Bandi developed a new synthetic method for preparing benzothiophene derivatives 95 based on tandem thia-Michael addition/intramolecular aldol reaction (a formal [3+2] annulation) between 1 and the cyclohexa-2,4-dien1-one monoketals 93 generated in situ by oxidative dearomatization with methanolic $\mathrm{Phl}(\mathrm{OAc})_{2}$ of phenols 92 to produce the corresponding tetrahydrobenzothiophenone derivatives 94, further converted to benzothiophenes by treatment with $4 \mathrm{~N} \mathrm{HCl}$ at $50{ }^{\circ} \mathrm{C}($ Scheme 33$) .{ }^{[67]}$

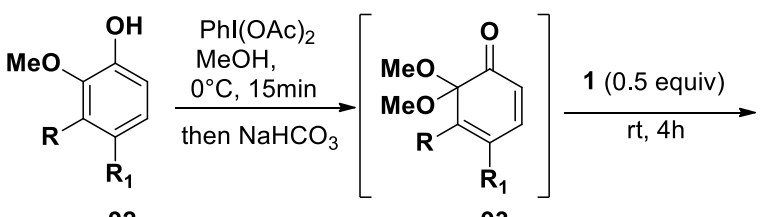

92

93

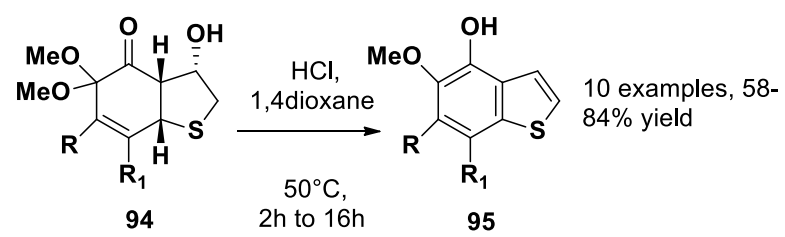

$\mathrm{R}=\mathrm{OMe}, \mathrm{Me}, \mathrm{CH}\left(\mathrm{OCH}_{2} \mathrm{CH}_{2} \mathrm{O}\right) \mathrm{CO}_{2} \mathrm{Me}, \mathrm{Br}, \mathrm{Cl}, \mathrm{t}-\mathrm{Bu}, \mathrm{H}$, $\mathrm{R}_{1}=\mathrm{H}, \mathrm{Cl}, \mathrm{Me}$

Scheme 33: Synthesis of benzothiophene derivatives via formal [3+2] annulation between 1 and cyclohexa-2,4-dien-1-one monoketals.

\section{Synthesis of 1,3-oxathiolane}


An efficient access to the chiral 1,3-oxathiolane motif was required to prepare bulk quantities of Lamivudine 96 and analogues 97-99 depicted in Figure 1.<smiles>Nc1ccn(C2CSC(CO)O2)c(=O)n1</smiles><smiles>Nc1ccn([C@@H]2COC(CO)S2)c(=O)n1</smiles>

Apricitabine (ATC)

Racivir (RCV)

Figure 1: Lamivudine 96 and analogues 97-99

Despite their structural simplicity, these compounds have represented a major synthetic challenge because of the need for a chemistry enabling stereochemical control of two potentially epimerizable stereocenters on the sulfurcontaining heterocycle. In 1995, a Glaxo research group described the synthesis of the chiral oxathiolane, the opening move being the reaction of glyoxylic acid monohydrate 100 and 1 in refluxing tert-butyl methyl ether under azeotropic conditions to give the trans hydroxy acid 101 in $58 \%$ yield $^{[68]}$ Its treatment with acetic anhydride in the presence of a catalytic amount of methanesulfonic acid provided a 1:2 mixture of the cis- and trans-acetoxy acid 102 and 103, with a combined yield of $83 \%$. The trans isomer 103 was isolated in form of white crystals from the mixture by fractional crystallization from benzene ( $22 \%$ based on a single isomer). After extensive efforts, the resolution of this compound has been achieved readily via its menthyl ester derivatives (Scheme 34).

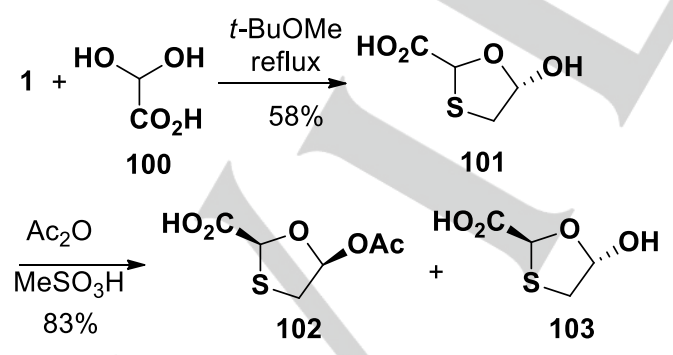

Scheme 34: reaction of glyoxylic acid monohydrate and 1 for access to the chiral 1,3-oxathiolane motif.

Ten years later, Whitehead and co-workers described a very efficient synthetic route for the partial enantioselective synthesis of lamivudine 96 - also known as 3TC - the key step being a highly effective dynamic resolution of the 5hydroxyoxathiolane, followed by chlorination and introduction of the cytosine residue. ${ }^{[69]}$ Initially, the 5-hydroxyoxathiolane was prepared by heating a mixture of menthyl glyoxylate hydrate 104 with 1,4-dithiane-2,5-diol in toluene. This procedure produced a mixture of four diastereoisomers 105 as a 35:35:15:15 ratio. Crystallization from $n$-hexane gave the desired diastereoisomer in $34 \%$ yield, corresponding to approximately all of the desired isomer in solution. To increase the yield of the desired diastereoisomer it was found that the rapid equilibration at C-5 occurred in dichloromethane or chloroform, giving a mixture of $\beta$ and $\alpha$ isomers, but no isomerisation at C-2 was observed. Access to enantiopure 5-acetoxyoxathiolane $107 \quad(2 R, 5 R)$ was explored by coupling reaction between commercially available $L$-menthyl glyoxylate monohydrate 104 and 1 , followed by treatment of the crude mixture with a $\mathrm{Et}_{3} \mathrm{~N}$ containing $n$-hexane solution, and this was found to provide hemiacetal 105 (60\% yield). After acetylation to 106, subsequent addition of $n$-hexane/Et ${ }_{3} \mathrm{~N}$ is claimed to enable both the rapid interconversion among the stereoisomers and the selective precipitation of the sole $(2 R, 5 R)$-stereoisomer 107 (Scheme 35). Recently, Palumbo and co-workers identified, in contrast with the aforementioned Whitehead's findings, two major acetate stereoisomers 106 having the $\mathrm{C} 2$ and C5 stereocenters in a trans relationship of hemiacetals. ${ }^{[70]}$

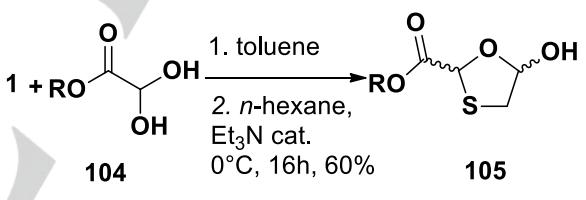

$\mathrm{R}=$ L-Menthyl

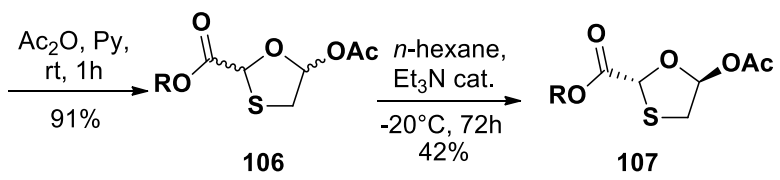

Scheme 35: Recent synthetic route for the partial enantioselective synthesis of lamivudine 96 .

In 2017, Mandala and co-workers were able to transfer the results of their improved batch synthesis of lamivudine 96 into continuous flow synthesis, the key intermediate 107 being prepared by an integrated two-step continuous flow process from L-menthyl glyoxalate hydrate 104 and 1 in a single solvent and $95 \%$ overall conversion. ${ }^{[71,72]}$

By taking advantage of the dynamic formation of hemithioacetals, an efficient, three-step synthesis of lamivudine through a surfactant-treated subtilisin Carlsberg (STS)-catalyzed dynamic kinetic resolution (DKR) protocol has been described by Ramström and co-workers (Scheme 36). ${ }^{[73]}$ Thus, the key enantioenriched 1,3-oxathiolane intermediate 109 for lamivudine was obtained by mixing 1 
and 108 in toluene in the presence of triethylamine as the base and phenyl acetate as acyl donor; furthermore, the enantiomer of lamivudine $\mathbf{1 1 0}$ was also accessible when STS was replaced by Candida antarctica lipase B (CAL B) (Scheme 36), thus representing a flexible stereocontrol in the asymmetric formation of five-membered oxathiolane derivatives.

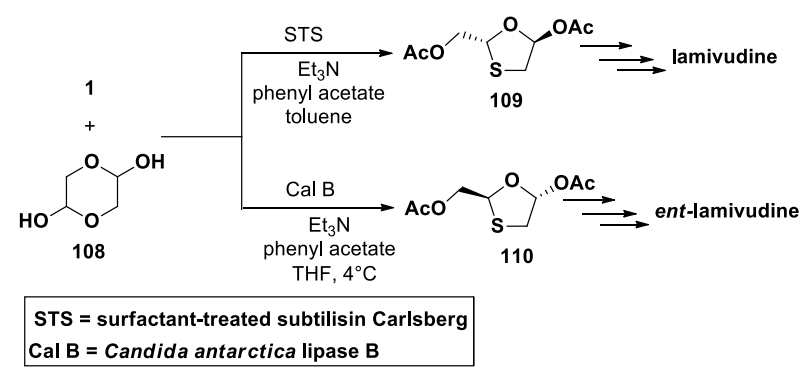

Scheme 36: Dynamic kinetic resolution of 1,3-oxathiolane from 1.

The great importance of the hemiacetal hydroxyl group is evidenced from the synthesis of the intermediate 112 using benzoyloxyacetaldehyde 111 where high ee were obtained with both CAL B and STS (Scheme 37). The origin of enantioenrichment in enzyme-catalyzed dynamic kinetic resolution of 1,3-oxathiolane derivatives, key intermediates for asymmetric lamivudine synthesis, was elucidated by the same group: the chirality control was determined by chiral HPLC and NOE NMR spectroscopy using a modified 1,3oxathiolane compound obtained through enzyme-catalyzed selective hydrolysis. Solvent-dependent stereoselectivity was observed under biphasic conditions using different organic solvents with phosphate buffer. ${ }^{[74]}$

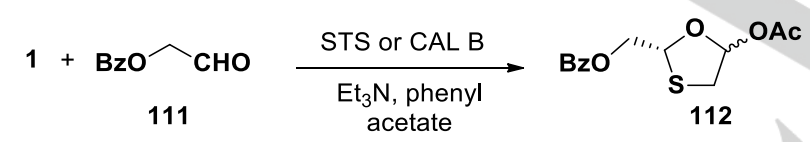

Scheme 37: Formation of 1,3-oxathiolane from 1

\section{Synthesis of 1,3-thiazoles and thiazolidines}

An organocatalytic enantio- and diastereoselective formal [3+2] annulation between imines 113 and 1 opened a rapid route to chiral thiazolidine-based molecules 114 starting from a readily available catalyst and achiral starting materials (Scheme 38 ). ${ }^{[75]}$ Thus, quinidine has been efficiently used to catalyze the enantio- and diastereoselective formal [3+2] annulation of imines 113 and 2-mercaptoacetaldehyde to assemble substitute thiazolidines 114. This bifunctional catalyst is able to activate both reaction partners, the sulfur addition to the imine being controlled by the chiral backbone. The subsequent cyclization occurred through addition of the nitrogen atom to the aldehyde group leading to the formation of the desired product.

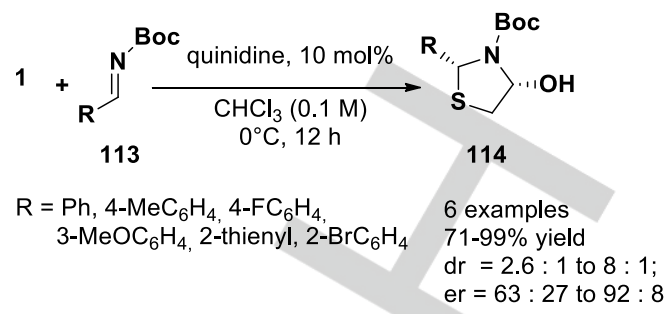

Scheme 38: Quinidine-catalyzed enantio- and diastereoselective formal [3+2] annulation of imines and 2-mercaptoacetaldehyde 2 for the assembly of substituted thiazolidines.

In 2016, two groups described the asymmetric formal [3+2] annulation of 1 to isatin-derived ketimines 115 as a facile and efficient method for the construction of chiral spirooxindole-4thiazolidines 116 using chiral squaramide catalysts 27 and 117 (Scheme 39). In the first case, the [3+2] annulation proceeded smoothly at $-20^{\circ} \mathrm{C}$ producing the major diastereomer 116 with 2:1 dr and $97 \%$ ee after 12 hours. ${ }^{[76]}$ These compounds were readily converted into the corresponding spirooxindole-4thiazolidinones 118 without loss of the enantioselectivity by simple oxidation, and have been successfully applied to the synthesis of a novel class of Mycobacterium tuberculosis inhibitors. Alternatively, spirocyclic 3-aminooxindoles were also obtained in very good yields (up to $95 \%$ ), with moderate to good diastereoselectivities (up to 9:1 dr) and very good enantioselectivities (up to $97 \%$ ee) through the same reaction in the presence of the chiral tertiary amine-squaramide catalyst $117 .^{[77]}$

$$
\begin{array}{ll}
\text { cat. } 117(20 \mathrm{~mol} \%) \\
\mathrm{DCM}, 24 \mathrm{~h}
\end{array}
$$

Scheme 39: Asymmetric formal [3+2] annulation of 1 to isatin-derived ketimines fort he synthesis of spirooxindole-4-thiazolidinones. 
Very recently, Silvani and coworkers described a one-pot, threecomponent reaction employed for the successful synthesis of biologically relevant, highly functionalized spirooxindole-fused 3thiazoline derivatives 121 (Scheme 40). ${ }^{[78]}$ Thus, application of an Asinger-type reaction to a series of substituted isatins 119 as the oxo component, ammonia and 2-mercaptoacetaldehyde 2 allowed to obtain efficiently a number of spirooxindole-fused 3thiazoline derivatives 121 through the intermediates $120 .^{[79-81]}$ The desired thiazolines were obtained with yields up to $81 \%$ for the most reactive $\mathrm{N}$-Me isatin through a simple and rapid protocol.

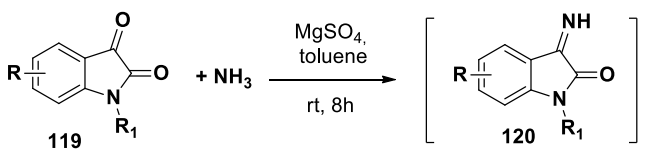

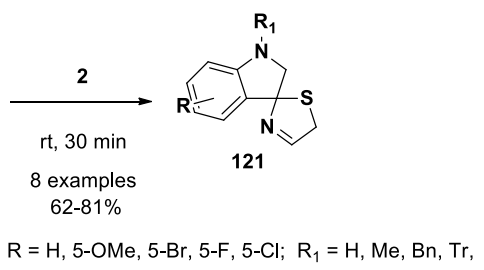

Scheme 40: Asinger-type reaction to substituted isatins, ammonia and 2mercaptoacetaldehyde $\mathbf{2}$ for the obtainment of spirooxindole-fused 3-thiazoline derivatives.

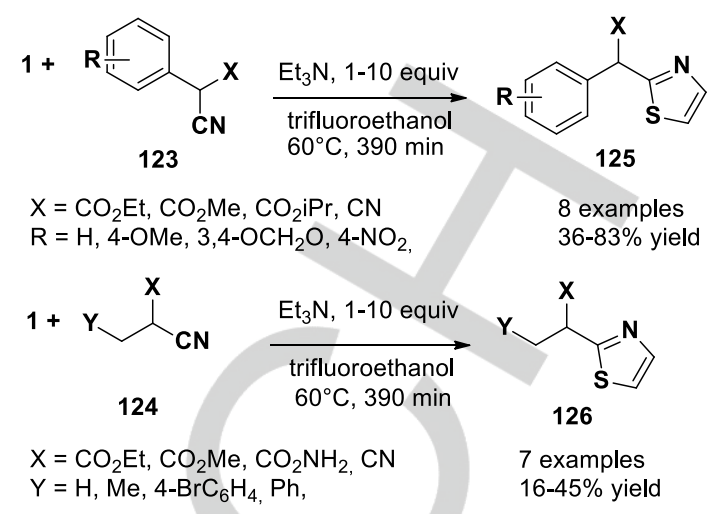

Scheme 42: Gewald-type reaction for the formation of the 2-aminothiophenes from 1,4-dithiane-2,5-diol 1 and appropriately substituted $\alpha$-methine nitrile.

In fact, Baxendale and co-workers demonstrated that the substitution by an alkyl or aryl group adjacent to the cyano group of the nitrile precursor predetermines the reaction outcome by blocking the Gewald-type mechanism responsible for the formation of the 2-aminothiophenes leading to the exclusive formation of 2-subsituted thiazoles 125 and 126 from readily available, air stable 1,4-dithiane-2,5-diol 1 as precursor for 2mercaptoacetaldehyde, and the appropriately substituted $\alpha-$ methine nitrile 123 and 124 (Scheme 42). ${ }^{\text {[83] }}$

\section{Synthesis of tetrahydropyranols} to the synthesis of all 20 common natural proteinogenic and four other $\alpha$-amino acid-isosteric $\alpha$-amino tetrazoles. ${ }^{[82]}$ The synthesis of cysteine analogue could not be obtained using mercaptoacetaldehyde dimer, the desired Ugi product being not formed; therefore, a different strategy was devised involving the use of 2,2-dimethylthiazolidine 122, a bench-stable liquid, well known to work as a Ugi-ready protected form of mercaptoacetaldehyde component in the classical Ugi-4 Component Reaction (CR). In the end, the target cysteine analogue was readily synthesized in good yields in one pot by another multi-component reaction, the Asinger-3CR of acetone, ammonia and mercaptoacetaldehyde dimer 1 (Scheme 41).

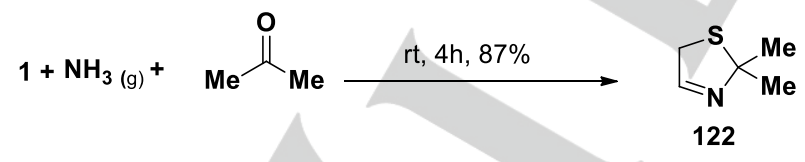

Scheme 41: Asinger-3CR of acetone, ammonia and mercaptoacetaldehyde dimer 1.

As above described, ${ }^{[55-59]} 1$ could be used as the aldehyde precursor in a modified Gewald reaction starting from nitriles to give 2-substituted aminothiophenes.
Catalytic $[3+3]$ annulation of 1 and activated cyclopropanes has been employed as an efficient reaction for the synthesis of thiazines and oxathianes. The cycloaddition reactions of donor-acceptor cyclopropanes represent powerful tools for the construction of various carbocycles and heterocycles and have been intensively studied in recent decades. ${ }^{[50]}$ Srinivasan and co-workers described the one-pot method for the synthesis of tetrasubstituted thiophenes 66 from tetrahydrothiopyranols 65 , in turn obtained from the $[3+3]$ annulation of trans-2-aroyl-3-arylcyclopropane-1,1dicarboxylates 64 with 1 in the presence of stoichiometric amounts of $\mathrm{AlCl}_{3}$ (Scheme 22). ${ }^{[49]}$ Interestingly, the $\mathrm{Sc}(\mathrm{OTf})_{3-}$ catalysed [3+3] annulation of cyclopropane 1,1-diesters 127 with 1 under mild reaction conditions allowed to obtain the synthesis of polyfunctionalized tetrahydrothiopyran derivatives 128 and 129 via a ring-opening/aldol cascade reaction (Scheme 43$){ }^{[84]}$

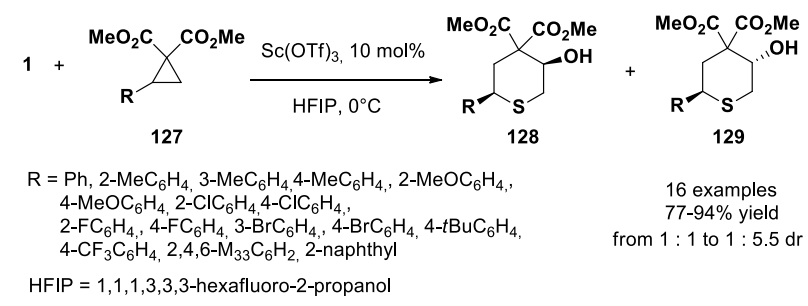


Scheme 43: Sc(OTf)3-catalysed [3+3] racemic annulation of cyclopropane 1,1diesters with $\mathbf{1}$ under mild conditions to obtain polyfunctionalized tetrahydrothiopyranols.

The reaction of donor/acceptor cyclopropanes with 1 reported by Zhang's and Sirinivasan's groups produced only racemic tetrahydrothiopyranol structures. ${ }^{[49,84]}$ Recently, Feng's group described a highly diastereo- and enantioselective [3+3] annulation of a number of aromatic substituted cyclopropyl ketones 130 acting as donor/acceptor cyclopropanes in the presence of $N, N^{\prime}$-dioxide-Sc(III) complex as the catalyst with 1 producing the corresponding chiral tetrahydrothiopyranols 131 in moderate yields, with excellent ee (up to $99 \%$ ee) and dr values (up to >19:1) (Scheme 44). ${ }^{[85]}$

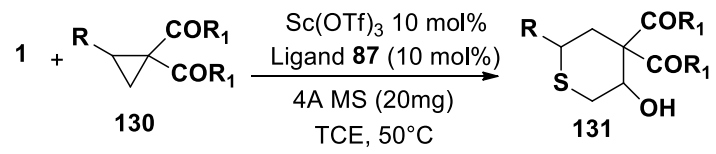

$\mathrm{R}=\mathrm{C}_{6} \mathrm{H}_{5}, 2-\mathrm{MeC}_{6} \mathrm{H}_{4}, 3-\mathrm{MeC}_{6} \mathrm{H}_{4}$,

4- $\mathrm{MeC}_{6} \mathrm{H}_{4}, 4-\mathrm{FC}_{6} \mathrm{H}_{4}, 3-\mathrm{ClC}_{6} \mathrm{H}_{4}, 4-\mathrm{ClC}_{6} \mathrm{H}_{4}$

$3-\mathrm{BrC}_{6} \mathrm{H}_{4}, 4 \mathrm{BrC}_{6} \mathrm{H}_{4}$

1-naphthyl, 2-naphthyl, vinyl

$\mathrm{R}_{1}=\mathrm{C}_{6} \mathrm{H}_{5}, 4-\mathrm{MeC}_{6} \mathrm{H}_{4}, 4-\mathrm{FC}_{6} \mathrm{H}_{4}$

Scheme 44: Diastereo- and enantioselective [3+3] annulation of a aromatic substituted cyclopropyl ketones in the presence of $N, N^{\prime}$-dioxide-Sc(III) complex with 1 for the production of chiral tetrahydrothiopyranols.

\section{Miscellaneous}

The versatility of 1,4-dithiane-2,5-diol for the synthesis of sulfur-containing heterocycles could be further illustrated by its application in the preparation of less common heterocyclic structures. Thus, an efficient domino reaction for the synthesis of enantioenriched, fused bisthiazolidines by generating an iminium ion followed by double cyclization has been described by Mahler and co-workers. ${ }^{[86]}$ This process leads efficiently to the creation of four new chemical bonds with high diastereoselectivity by treatment of aminothiols in ethanol in the presence of catalytic tosic acid. The products derived from cysteamine 132a or L-cysteine ethyl ester 132b produced a mixture of the anti-133a or $133 b$ and syn-134 or $134 \mathrm{~b}$, respectively, in excellent yields while the aromatic aminothiol 135 led to the formation of fused tricycle 136 as the only diastereomer (Scheme 45). The regioselectivity of the transformation could be explained on the basis of theoretical calculations.

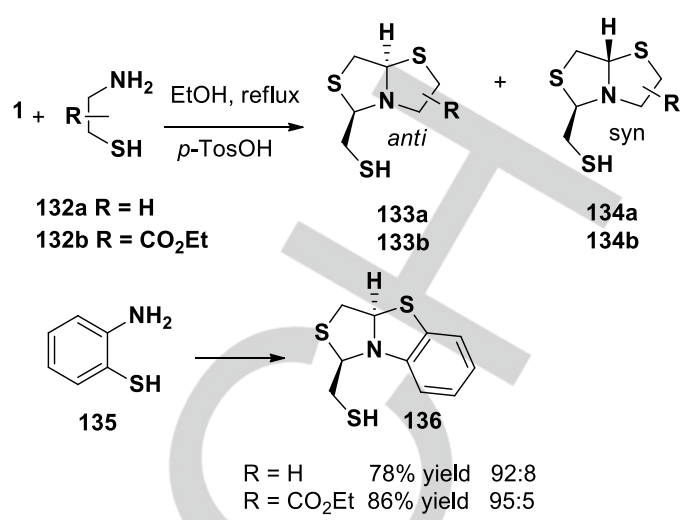

Scheme 45: Domino procedure for the synthesis of enantioenriched, fused bisthiazolidines from 1,4-dithiane-2,5-diol and cysteamine or L-cysteine.

Notably, the reaction of linear $\beta$-aminoalcohols such as 137 with 1 for the preparation of the corresponding thiazolo[4,3b]oxazole bicycles is more complicated, leading to the formation of oxazolidinylthiazolidines 139 and/or dithioazabicycles 138 as the main products, the correct structure of dithioazabicycle being previously misassigned as bisthiiranes. The distribution pattern depends mainly on the position of the aminoalcohol substituents (Scheme 46). ${ }^{[87]}$

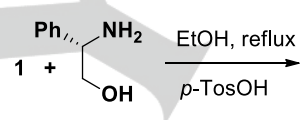

137<smiles>OCC(c1ccccc1)N1C2CSC1CS2</smiles>

(S)-138<smiles>OC[C@H](c1ccccc1)N1C2[CH-]C1SC2</smiles>

$(R)-138$<smiles>SC[C@@H]1SC[C@@H]2OC[C@@H](c3ccccc3)N21</smiles>

(S)-139
Scheme 46: Linear $\beta$-aminoalcohols reaction with 1 for the preparation of thiazolo[4,3-b]oxazole bicycles and oxazolidinylthiazolidines

In 2012, an efficient one-step preparation of a series of $\mathrm{N}$ substituted-2,5-dithia-7-azabicyclo[2.2.1]heptanes

bearing different substituents involved the reaction of various primary amines 140 with 1 in the presence of a catalytic amount of $\mathrm{Mg}$ (II) ions in water (Scheme 47).
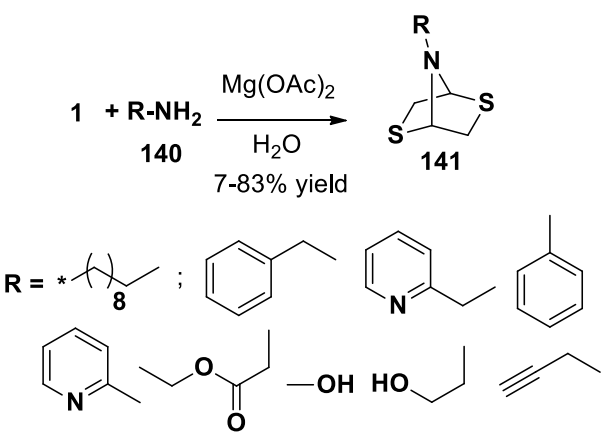

Scheme 47: One-step preparation of $N$-substituted-2,5-dithia-7azabicyclo[2.2.1]heptanes from primary amines with 1 in the presence of $\mathrm{Mg}(\mathrm{II})$ ions. 
The ability of compounds 141 to bind to gold surfaces was assessed by a number of trechniques, such as cyclic voltammetry, electrochemical impedance spectroscopy ToFSIMS, and XPS, and it was found that these novel bicyclic sulfides interact favourably with gold surfaces, with minimal fragmentation. However, the adsorption and film packing properties were greatly compromised by an $N$-pyridyl substitution. The findings then indicate that the surface behaviour of $\mathrm{N}$-substituted 2,5-dithia-7azabicyclo[2.2.1] heptanes varies with respect to the $\mathrm{N}$ substitution and the nature of the substituent, suggesting that the adsorption profiles and the film packing of bicyclic sulfides on gold surfaces are highly dependent on the binding interface and the molecular orientation.

Excellent yields of 1,4-dithiin 142 were obtained by heating a dry DMF solution of 1 and 2.5 equivalents of thionyl chloride to reflux (Scheme 48). ${ }^{[89]}$

$$
1 \underset{140-160^{\circ} \mathrm{C}}{\left.\stackrel{\mathrm{SOCl}_{2}, \mathrm{DMF}}{\mathrm{S}}\right]}
$$

Scheme 48: Synthesis of 1,4-dithiin142.

A particular attention has been recently devoted to 1,4-dithiins owing to their unique electronic and conducting properties as well as their use for the preparation of different sulfur heterocycles. ${ }^{[90]}$

Perumal and co-workers described a facile and efficient synthesis of novel 3-aryl-5,6-dihydro-1,4,2-oxathiazin-6-ols 144 presumably involving the concomitant in situ generation in the presence of triethylamine of both 2-mercaptoacetaldehyde 2 and $(E)-N$-hydroxyarylimidoyl chlorides 143 for the required $[3+3]$ annulation. (Scheme 49). ${ }^{[91]}$

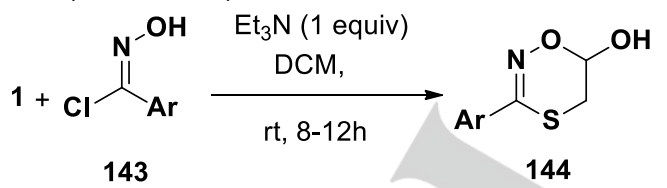

$\mathrm{Ar}=4-\mathrm{ClC}_{6} \mathrm{H}_{4}, 4-\mathrm{BrC}_{6} \mathrm{H}_{4}, 4-\mathrm{PhC}_{6} \mathrm{H}_{4}, \quad 15$ examples 4- $\mathrm{EtC}_{6} \mathrm{H}_{4}, 4-\mathrm{PPrC}_{6} \mathrm{H}_{4}, 4-\mathrm{tBuC}_{6} \mathrm{H}_{4} \mathrm{C}_{6} \mathrm{H}_{5}, \quad 65-88 \%$ yield $2-\mathrm{MeC}_{6} \mathrm{H}_{4}, 3-\mathrm{FC}_{6} \mathrm{H}_{4}, 3-\mathrm{BrC}_{6} \mathrm{H}_{4}$,

1-naphthyl, 2-naphthyl, 2-thienyl,

2-benzothienyl

Scheme 49: Synthesis of novel 3-aryl-5,6-dihydro-1,4,2-oxathiazin-6-ols from the reaction of $(E)-N$-hydroxyarylimidoyl chlorides and 1 in the presence of triethylamine.

Recently, a one-pot base-catalysed strategy for an approach to 1,4-thiazines 146 obtained in total atom economy and in quantitative yields was based on sulfa-Michael addition/formal [3+3] annulation cascade reaction between 1 and 1,2-diaza-1,3dienes $\mathbf{1 4 5}$, as reported by Attanasi and coworkers (Scheme 50). ${ }^{[92]}$

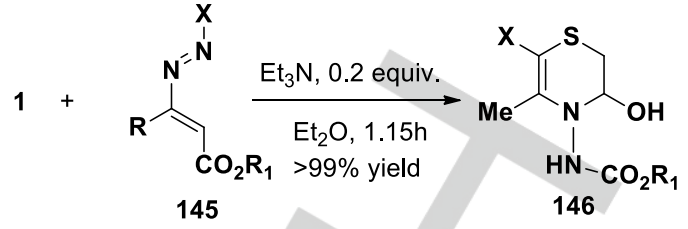

$$
\begin{aligned}
& \mathrm{R}=\mathrm{Me}, n \mathrm{Pr}, \\
& \mathrm{R}_{1}=t \mathrm{Bu}, \mathrm{Me}, \mathrm{Et} \\
& \mathrm{X}=\mathrm{CO}_{2} \mathrm{Me}, \mathrm{Co}_{2} \mathrm{Et}, \mathrm{CO}_{2} \mathrm{Bn} . \\
& \quad \mathrm{CO}_{2} \mathrm{Menthyl},(\mathrm{OMe})_{2} \mathrm{P}=\mathrm{O}
\end{aligned}
$$

11 examples

Scheme 50: Synthesis of 1,4-thiazines 146 via sulfa-Michael addition/formal $[3+3]$ annulation cascade reaction between 1 and 1,2-diaza-1,3-dienes.

An unusual diastereoselective [3+3] cycloaddition of 1 with azomethine imines 147 catalyzed by DABCO. ${ }^{[93]}$ has been proposed as a useful way to prepare a variety of highly functionalized six-membered dinitrogen-fused sulfur-containing heterocycles 148 in good to high yields (75-96\%) with excellent diastereoselectivities (>20:1 dr). (Scheme 51).Azomethine imines bearing electron-rich and electron-deficient groups at different positions on the aromatic ring could be efficiently used allowing to obtain very interesting heterocyclic products through a synthetically practical methodology also applicable in a gramscale with a simple workup.<smiles>[R]C=[N+]1CCC(=O)N1</smiles>

147<smiles>[R]C1SC[C@@H](O)N2C(=O)CCN12</smiles>
148
$\mathrm{R}=\mathrm{Ph}, 2-\mathrm{MeC}_{6} \mathrm{H}_{4}, 3-\mathrm{MeC}_{6} \mathrm{H}_{4}, 4-\mathrm{MeC}_{6} \mathrm{H}_{4}, 17$ examples 4- $\mathrm{MeOC}_{6} \mathrm{H}_{4}, 2-\mathrm{ClC}_{6} \mathrm{H}_{4}, 4-\mathrm{BrC}_{6} \mathrm{H}_{4}, \quad \mathrm{dr}>20: 1$ 4- $\mathrm{CNC}_{6} \mathrm{H}_{4}$, 2-naphthyl , (E)-styryl, 2-furyl, 3-pyridyl, $n$-pentyl $\quad 75-96 \%$ yield

Scheme 51: Diastereoselective [3+3] cycloaddition of 1 with azomethine imines 147 for the synthesis of highly functionalized six-membered dinitrogenfused heterocycles,

This reaction has been theoretically studied using DFT computational calculations to gain insights of the mechanisms and to explain the observed diastereoselectivity. A plausible catalytic cycle has been proposed, the tertiary amine of the catalyst providing suitable basicity to enhance the nucleophilicity of mercaptoacetaldehyde generated from 1 under equilibrium conditions. ${ }^{[94]}$

Later, the kinetic resolution of the azomethine imines has been successfully obtained with high selectivity factors ( $S$ factor up to 67). The base-catalyzed [3+3] annulation of the resolved enantioenriched azomethine imine $R-149(R=P h, 91 \%$ ee) with 1 in the presence of $1 \mathrm{~mol} \%$ of DABCO proceeded smoothly in $20 \mathrm{~min}$ to produce the highly functionalized sulfur-containing heterocycle 150 in $92 \%$ yield with exclusive diastereoselectivity and maintained enantioselectivity (Scheme 52). ${ }^{[95]}$ 
<smiles>CO[13C](=O)[O-]</smiles>

$91 \%$ ee<smiles>O=C1CC(c2ccccc2)N2C(=O)SCC(O)N12</smiles>

$92 \%$ yield $90 \%$ ee $>20: 1 d r$
Scheme 52: Base-catalyzed [3+3] annulation of resolved enantioenriched azomethine imine R-149 with 1 for the synthesis of highly functionalized sulfurcontaining heterocycle 150 .

A domino reaction of aryl isothiocyanates 151 and 1 under solvent- and catalyst-free microwave irradiation paved the way for a highly atom efficient synthesis of 4-hydroxy-3arylthiazolidine-2-thiones 152. (Scheme 53). ${ }^{[96]}$ This sequence could be also applied to aryl isocyanates to afford 3phenylthiazol-2(3H)-ones in good yields.

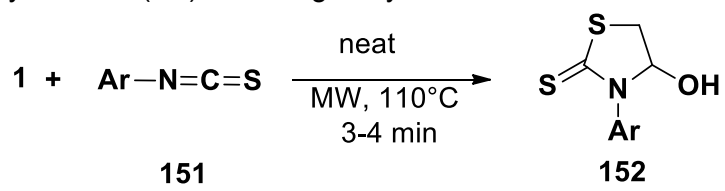

Scheme 53: Synthesis of 4-hydroxy-3-arylthiazolidine-2-thiones 152 through novel domino reactions of aryl isothiocyanates 151 and 1 under solvent- and catalyst-free microwave irradiation.

In 2017, functionalized thiazine and oxathiane derivatives 154 have been efficiently built up through Lewis acid catalyzed $[3+3]$ annulation of $N$-tosylaziridine dicarboxylates and oxiranes 153 with in situ generated mercaptoaldehyde. ${ }^{[97]}$

(Scheme 54).

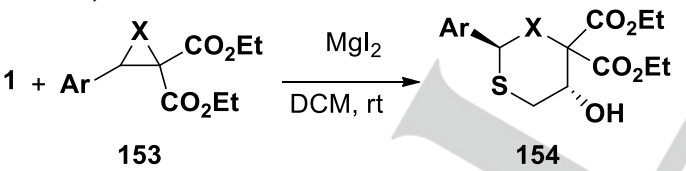

$$
\begin{aligned}
& \mathrm{X}=\mathrm{N} \text {-Ts } \quad \mathrm{X}=\mathrm{O} \\
& 12 \text { examples } 4 \text { examples } \\
& 72-87 \% \text { yield } \quad 74-82 \% \text { yield }
\end{aligned}
$$

Scheme 54: Lewis acid-catalyzed $[3+3]$ annulation of $N$-tosylaziridine dicarboxylates and oxiranes 153 with in situ generated mercaptoaldehyde 2 for the synthesis of functionalized thiazine and oxathiane derivatives.

\section{Conclusions}

The long journey of 1,4-dithiane-2,5-diol around the synthesis of sulfurated heterocycles is far to be concluded. This overview summarized the applications of a versatile and inexpensive starting material for the synthesis of a variety of sulfur containing heterocycles. It is relevant to underline the ability of 2-mercaptoacetaldehyde to function as a useful platform molecule for the synthesis of important heterocycles, including thiophene and 1,3-thiazole families and, more generally, for development of new, organocatalytic asymmetric reactions.

Moreover, the use of 1 as a C2 synthon for the construction of nitrogen-containing heterocycles rather than sulfurcontaining heterocycles via desulfurization has been recently described by Wu's group: the synthesis of 2- acylquinolines from methyl ketones and arylamines using 1,4-dithane-2,5diol as an ethylene surrogate represents a further demonstration of its versatility in heterocyclic chemistry. ${ }^{[8]}$

Keywords: 1,4-Dithiane-2,5-diol; Heterocycles; Thiophene; Michael/Aldol reactions.

[1] S. Benetti, C. De Risi, G. P. Pollini, V. Zanirato, Chem Rev. 2012, 112, 2129-2163.

[2] P. Chauhan, S. Mahajan, D. Enders, Chem. Rev. 2014 114, 8807-8864.

[3] F. Effenberger, A. Straub, V. Null, Liebigs Ann. der Chemie 1992, 12, 1297-1301.

[4] A. Barco, N. Baricordi, S. Benetti, C. De Risi, G. P. Pollini, Tetrahedron Lett. 2006, 47, 8087-8090.

[5] R. A. Bunce, J. D. Pierce, Tetrahedron Lett. 1986, 27, 5583-5586.

[6] H. Li, L. Zu, H. Xie, J. Wang, W. Jiang, W. Wang, Org. Lett. 2007, 9, 1833-1835.

[7] C. Yu, Y. Zhang, A. Song, Y. Ji, W. Wang, Chem. A Eur J. 2011, 17, 770-774.

[8] N. Baricordi, S. Benetti, V. Bertolasi, C. De Risi, G. P. Pollini, F. Zamberlan, V. Zanirato, C. De Risi, G. P. Pollini, F. Zamberlan, et al., Tetrahedron 2012, 68, 208213.

[9] J. Song, J. Moss, D.-C. Yang, Z. Guan, Y.-H. He, RSC Adv. 2014, 4, 54032-54038.

[10] H. Yan, H. B. Jang, J.-W. Lee, H. K. Kim, S. W. Lee, J. W. Yang, C. E. Song, Angew. Chem. Int. Ed. Engl. 2010, 49, 8915-8917.

[11] M. Duan, Y. Liu, J. Ao, L. Xue, S. Luo, Y. Tan, W. Qin C. E. Song, H. Yan, Org. Lett. 2017, 19, 2298-2301.

[12] Y. Zhang, P. Vongvilai, M. Sakulsombat, A. Fischer, O. Ramström, Adv. Synth. Catal. 2014, 356, 987-992.

[13] E. H. Krenske, R. C. Petter, K. N. Houk, J. Org. Chem. 2016, 81, 11726-11733.

[14] J.-B. Ling, Y. Su, H.-L. Zhu, G.-Y. Wang, P.-F. Xu, Org. Lett. 2012, 14, 1090-1093.

[15] P. Chauhan, S. Mahajan, U. Kaya, D. Hack, D. Enders, Adv. Synth. Catal. 2015, 357, 253-281.

[16] Y. Su, J.-B. Ling, S. Zhang, P.-F. Xu, J. Org. Chem. 2013, 78, 11053-11058.

[17] C. Xu, J. Du, L. Ma, G. Li, M. Tao, W. Zhang, Tetrahedron 2013, 69, 4749-4757.

[18] M. Hans, L. Delaude, J. Rodriguez, Y. Coquerel, J. Org. Chem. 2014, 79, 2758-2764.

[19] S. Nagaraju, N. Satyanarayana, B. Paplal, A. K. Vasu, S. Kanvah, B. Sridhar, P. Sripadid, D. Kashinath, RSC Adv. 2015, 5, 94474-94478.

[20] H. Ishitani, Y. Saito, T. Tsubogo, S. Kobayashi, Org. Lett. 2016, 18, 1346-1349. 
[21] S. Nagaraju, K. Satish, B. Paplal, D. Kashinath, Tetrahedron Lett. 2017, 58, 2865.

[22] Y. Zheng, C. M. Tice, S. B. Singh, Bioorg. Med. Chem. Lett. 2014, 24, 3673-3682.

[23] B. Mondal, S. Nandi, S. C. Pan, European J. Org. Chem. 2017, 2017, 4666-4677.

[24] S.-W. Duan, Y. Li, Y.-Y. Liu, Y.-Q. Zou, D. Q. Shi, W.-J. Xiao, Chem. Commun. 2012, 48, 5160-5162.

[25] P. Zhou, Y. Cai, L. Lin, X. Lian, Y. Xia, X. Liu, X. Feng, Adv. Synth. Catal. 2015, 357, 695-700.

[26] B.-L. Zhao, L. Liu, D.-M. Du, European J. Org. Chem. 2014, 7850-7858

[27] J.-J. Liang, J.-Y. Pan, D.-C. Xu, J.-W. Xie, Tetrahedron Lett. 2014, 55, 6335-6338.

[28] Y.-J. Hu, X.-B. Wang, S.-Y. Li, S.-S. Xie, K. D. G. Wang, L.-Y. Kong, Tetrahedron Lett. 2015, 56, 105-108.

[29] D. Kowalczyk, J. Wojciechowski, Ł. Albrecht, Tetrahedron Lett. 2016, 57, 2533-2538.

[30] S. V. Kumar, P. Prasanna, S. Perumal, Tetrahedron Lett. 2013, 54, 6651-6655.

[31] S. Mahajan, P. Chauhan, M. Blümel, R. Puttreddy, K. Rissanen, G. Raabe, D. Enders, Synthesis 2016, 48, 1131-1138.

[32] J. Hejmanowska, Ł. Albrecht, ARKIVOC 2016, V, 225241.

[33] C. Bharkavi, S. V. Kumar, S. Perumal, Synlett 2015, 26, 1665-1670.

[34] Y.-Y. Gui, J. Yang, L.-W. Qi, X. Wang, F. Tian, X.-N. Li, L. Peng, L.-X. Wang, Org. Biomol. Chem. 2015, 13, 6371-6379.

[35] G. Cai, S. Liu, J. Zhang, Y. Ren, H. Wang, Z. Miao, Synth. Commun. 2016, 46, 793-798.

[36] U. Kaya, S. Mahajan, J.-H. Schöbel, A. Valkonen, K. Rissanen, D. Enders, Synthesis (Stuttg). 2016, 48, 4091-4098.

[37] S. Meninno, J. Overgaard, A. Lattanzi, Synthesis (Stuttg). 2017, 49, 1509-1518.

[38] Y. Huang, C. Zheng, Z. Chai, G. Zhao, Adv. Synth. Catal. 2014, 356, 579-583.

[39] J. Duan, J. Cheng, B. Li, F. Qi, P. Li, European J. Org. Chem. 2015, 6130-6134.

[40] N. Baricordi, S. Benetti, C. De Risi, M. Fogagnolo, G. P. Pollini, V. Zanirato, Lett. Org. Chem. 2009, 6, 593-597.

[41] J. Tang, D. Q. Xu, A. B. Xia, Y. F. Wang, J. R. Jiang, S. P. Luo, Z. Y. Xu, Adv. Synth. Catal. 2010, 352, 21212126.

[42] A. Zaghi, T. Bernardi, V. Bertolasi, O. Bortolini, A. Massi, C. De Risi, J. Org. Chem. 2015, 80, 9176-9184.

[43] C. De Risi, S. Benetti, M. Fogagnolo, V. Bertolasi, Tetrahedron Lett. 2013, 54, 283-286.

[44] Y. Xiang, J. Song, Y. Zhang, D.-C. Yang, Z. Guan, Y.-H. He, J. Org. Chem. 2016, 6042-6048.

[45] O. W. Gooding, C. C. Beard, Heterocycles 1991, 32, 1777-1780.

[46] C. J. O’Connor, M. D. Roydhouse, A. M. Przybył, M. D. Wall, J. M. Southern, J. Org. Chem. 2010, 75, 25342538.

[47] N. McNabola, C. J. O'Connor, M. D. Roydhouse, M. D. Wall, J. M. Southern, Tetrahedron 2015, 71, 4598-4603.

[48] W. Shi, L. Wan, Y. Hu, S. Sun, W. Li, Y. Peng, M. Wu, H. Guo, J. Wang, Tetrahedron Lett. 2015, 56, 20832085.

[49] G. Sathiskannan, K. Srinivasan, Chem. Commun. 2014, 50, 4062-4064.

[50] T. Selvi, G. Vanmathi, K. Srinivasan, RSC Adv. 2015, 5, 49326-49329.
[51] G. Bharathiraja, G. Sathishkannan, T. Punniyamurthy, J. Org. Chem. 2016, 81, 2670-2674.

[52] C. Ni, M. Wang, X. Tong, Org. Lett. 2016, 18, 2240 2243.

[53] C. S. Pradeepa Kumara, G. Byre Gowda, K. S. Vinay Kumar, N. Ramesh, M. P. Sadashiva, H. Junjappa, Tetrahedron Lett. 2016, 57, 4302-4305.

[54] Z. Puterová, A. Krutošíková, D. Végh, ARKIVOC 2010, 209-246.

[55] K. Gewald, E. Schinke, H. Böttcher, Chem. Ber. 1966, 99, 94-100.

[56] K. Wang, D. Kim, A. Doemling, J. Comb. Chem. 2010, 12, 111-118.

[57] B. Dumaître, N. Dodic, J. Med. Chem. 1996, 39, 16351644.

[58] M. Gutschow, U. Neumann, J. Med. Chem. 1998, 41, 1729-1740.

[59] S. Hesse, E. Perspicace, G. Kirsch, Tetrahedron Lett. 2007, 48, 5261-5264.

[60] L. Ma, L. Yuan, C. Xu, G. Li, M. Tao, W. Zhang, Synthesis (Stuttg). 2012, 45, 45-52.

[61] G. A. Eller, W. Holzer, Molecules 2006, 11, 371-376.

[62] B. Chen, H. Ni, X. Guo, G. Zhang, Y. Yu, RSC Adv. 2014, 4, 44462-44465.

[63] W. Shi, S. Sun, Y. Hu, T. Gao, Y. Peng, M. Wu, H. Guo, J. Wang, Tetrahedron Lett. 2015, 56, 3861-3863.

[64] S. V. Kumar, S. Muthusubramanian, J. C. Menéndez, S Perumal, Beilstein J. Org. Chem. 2015, 11, 1707-1712.

[65] E. C. Vatansever, K. Kılıç, M. S. Ozer, G. Koza, N. Menges, M. Balci, Tetrahedron Lett. 2015, 56, 53865389.

[66] L. Yao, Q. Zhu, L. Wei, Z.-F. Wang, C.-J. Wang, Angew. Chemie Int. Ed. 2016, 55, 5829-5833.

[67] S. K. Chittimalla, C. Bandi, Synlett 2017, 28, 1051-1056.

[68] H. J. Jin, M. A. Siddiqui, C. A. Evans, H. L. A. Tse, T. S. Mansour, M. D. Goodyear, P. Ravenscroft, C. D. Beels, J. Org. Chem. 1995, 60, 2621-2623.

[69] M. D. Goodyear, M. L. Hill, J. P. West, A. J. Whitehead, Tetrahedron Lett. 2005, 46, 8535-8538.

[70] M. F. Caso, D. D'Alonzo, S. D'Errico, G. Palumbo, A. Guaragna, Org. Lett. 2015, 17, 2626-2629.

[71] D. Mandala, S. Chada, P. Watts, Org. Biomol. Chem. 2017, 15, 3444-3454.

[72] D. Mandala, P. Watts, ChemistrySelect 2017, 2, 11021105.

[73] L. Hu, F. Schaufelberger, Y. Zhang, O. Ramström, Chem. Commun. 2013, 49, 10376.

[74] L. Hu, Y. Ren, O. Ramström, J. Org. Chem. 2015, 80, 8478-8481.

[75] H. Qian,J. Sun, Asian J.Org. Chem. 2014, 3, 387-390.

[76] P. Cheng, W. Guo, P. Chen, Y. Liu, X. Du, C. Li, Chem. Commun. 2016, 52, 3418-3421.

[77] B. Feng, J. Yang, J. Li, X. Li, Tetrahedron Lett. 2016, 57 3457-3461.

[78] G. Rainoldi, F. Begnini, A. Silvani, G. Lesma, Synlett 2016, 27, 2831-2835.

[79] M. Thiel, F. Asinger, K. Schmiedel, Justus Liebigs Ann.Chem. 1958, 611, 121-131.

[80] F. Asinger, H. Offermanns, Angew. Chemie Int. Ed. 1967, 6, 907-919.

[81] F. Asinger, A. Saus, M. Bähr-Wirtz, Liebigs Ann. der Chemie 1979, 708-726.

[82] T. Zhao, K. Kurpiewska, J. Kalinowska-Tłuscik, E. Herdtweck, A. Dömling, Chem. A Eur. J. 2016, 22, 3009-3018.

[83] C. J. Mallia, L. Englert, G. C. Walter, I. R. Baxendale, 
Beilstein J. Org. Chem. 2015, 11, 875-883.

[84] H.-P. Wang, H.-H. Zhang, X.-Q. Hu, P.-F. Xu, Y.-C. Luo, European J. Org. Chem. 2015, 3486-3494.

[85] X. Fu, L. Lin, Y. Xia, P. Zhong, X. Liu, X. Feng, Org. Biomol. Chem. 2016, 14, 5914-5917.

[86] C. Saiz, V. Castillo, S. G. Mahl, Synlett 2012, 23, 10901094.

[87] C. Saiz, V. Villamil, M. M. González, M. A. Rossi, L. Martínez, L. Suescun, A. J. Vila, G. Mahler,

Tetrahedron: Asymmetry 2017, 28, 110-117.

[88] S. Ramsaywack, S. Martić, S. Milton, L. Gates, A. S. Grant, M. Labib, A. Decken, H.-B. Kraatz, J. Phys. Chem. C 2012, 116, 7886-7896.

[89] A. S. Grant, S. Faraji-Dana, E. Graham, J. Sulfur Chem. 2009, 30, 135-136.

[90] A. Castelló-Micó, J. Nafe, K. Higashida, K. Karaghiosoff, M. Gingras, P. Knochel, Org. Lett. 2017, 19, 360-363.

[91] S. V. Kumar, S. Muthusubramanian, S. Perumal, RSC
Adv. 2015, 5, 90451-90456.

[92] G. Mari, G. Favi, L. De Crescentini, S. Santeusanio, O. A. Attanasi, F. Mantellini, Asian J. Org. Chem. 2016, 5, 705-709.

[93] X. Fang, J. Li, H.-Y. Tao, C.-J. Wang, Org. Lett. 2013, 15, 5554-5557.

[94] L. Zheng, Y. Qiao, M. Lu, J. Chang, Org. Biomol. Chem. 2015, 13, 7558-7569.

[95] L. Wei, Z.-F. Wang, L. Yao, G. Qiu, H. Tao, H. Li, C.-J. Wang, Adv. Synth. Catal. 2016, 358, 3955-3959.

[96] S. V. Kumar, S. Perumal, Tetrahedron Lett. 2014, 55, 3761-3764.

[97] R. K. Varshnaya, P. Banerjee, Org. Biomol. Chem. 2017, 15, 5182-5190.

[98] X. Wu, X. Geng, P. Zhao, J. Zhang, X. Gong, Y. Wu, A. Wu, Org. Lett. 2017, 19, 1550-1553. 
Entry for the Table of Contents (Please choose one layout)

Layout 1:

\section{MICROREVIEW}

\section{Text for Table of Contents:}

This microreview highlights the utility of 1,4- dithiane-2,5diol as the cheap and commercially available starting material for use in organic and medicinal chemistry synthesis.
Key Topic*Heterocyclic Chemistry

\section{Francesco Zamberlan, ${ }^{[a]}$ Anna} Fantinati, ${ }^{[b]}$ Claudio Trapella ${ }^{*[b]}$

Page No. - Page No.

Title 1,4-Dithiane-2,5-diol: An Attractive Platform for the Synthesis of Sulfur Containing Functionalized Heterocycles 